\title{
Potent Antimicrobial and Antibiofilm Activities of Feleucin-K3 Analogs Modified by $\alpha$-(4-Pentenyl)-Ala against Multidrug-Resistant Bacteria
}

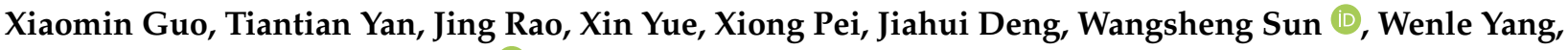 \\ Bangzhi Zhang and Junqiu Xie *(D)
}

check for updates

Citation: Guo, X.; Yan, T.; Rao, J.; Yue, X.; Pei, X.; Deng, J.; Sun, W.; Yang, W.; Zhang, B.; Xie, J. Potent Antimicrobial and Antibiofilm Activities of Feleucin-K3 Analogs Modified by $\alpha$-(4-Pentenyl)-Ala against Multidrug-Resistant Bacteria. Biomolecules 2021, 11, 761. https:// doi.org/10.3390/biom11050761

Received: 24 April 2021

Accepted: 16 May 2021

Published: 19 May 2021

Publisher's Note: MDPI stays neutral with regard to jurisdictional claims in published maps and institutional affiliations.

Copyright: (C) 2021 by the authors Licensee MDPI, Basel, Switzerland. This article is an open access article distributed under the terms and conditions of the Creative Commons Attribution (CC BY) license (https:// creativecommons.org/licenses/by/ $4.0 /)$
Key Laboratory of Preclinical Study for New Drugs of Gansu Province, School of Basic Medical Sciences \& Research Unit of Peptide Science, Chinese Academy of Medical Sciences, 2019RU066, Lanzhou University, Lanzhou 730000, China; guoxm17@lzu.edu.cn (X.G.); yantt19@lzu.edu.cn (T.Y.); raoj18@lzu.edu.cn (J.R.); yuex20@lzu.edu.cn (X.Y.); peix18@1zu.edu.cn (X.P.); dengjh18@lzu.edu.cn (J.D.); sunws@lzu.edu.cn (W.S.); yangw1@lzu.edu.cn (W.Y.); zhangbz@lzu.edu.cn (B.Z.)

* Correspondence: xiejq@lzu.edu.cn; Tel.: +86-931-891-5522; Fax: +86-931-891-1255

\begin{abstract}
The dramatic increase in antimicrobial resistance (AMR) highlights an urgent need to develop new antimicrobial therapies. Thus, antimicrobial peptides (AMPs) have emerged as promising novel antibiotic alternatives. Feleucin-K3 is an amphiphilic $\alpha$-helical nonapeptide that has powerful antimicrobial activity. In our previous study, it was found that the fourth residue of Feleucin-K3 is important for antimicrobial activity. After $\alpha$-(4-pentenyl)-Ala was introduced into this position, both the antimicrobial activity and stability were greatly improved. Herein, to improve the limitations of Feleucin-K3, this unnatural amino acid was further introduced into different positions of FeleucinK3. Among these synthetic Feleucin-K3 analogs, the N-terminal-substituted analog Feleucin-K65 (K65) and C-terminal-substituted analog Feleucin-K70 (K70) had preferable antimicrobial activity. In particular, their antimicrobial activities against multidrug-resistant bacteria were more potent than that of antibiotics. The stabilities of these peptides in salt and serum environments were improved compared with those of Feleucin-K3. In addition, these analogs had low hemolytic activity and AMR. More importantly, they effectively inhibited biofilm formation and exhibited considerable efficacy compared with traditional antibiotics against biofilm infection caused by methicillin-resistant Staphylococcus aureus (MRSA). In antimicrobial mechanism studies, K65 and K70 mainly permeated the outer membrane and depolarized the cytoplasmic membrane, resulting in cellular component leakage and cell death. In summary, analogs K65 and K70 are potential antimicrobial alternatives to solve the antibiotic crisis.
\end{abstract}

Keywords: antimicrobial peptide analogs; unnatural hydrophobic amino acid; $\alpha$-(4-pentenyl)-Ala; antimicrobial activity; antibiofilm activity

\section{Introduction}

The development of antibiotic drugs has greatly reduced the incidence and mortality of bacterial infections [1]. However, the overreliance on antibiotics has aggravated the antimicrobial resistance (AMR), thereby seriously threatening global public health [2]. Antimicrobial peptides (AMPs) have broad-spectrum antimicrobial activity due to their rapid bactericidal ability and mechanism of action, which is mainly through nonspecific membrane destruction, attracting widespread attention as promising new antibiotic candidates [3]. In addition, the formation of biofilms has always been considered one of the main reasons by which bacteria develop resistance, making it more difficult for conventional antibiotics to treat bacterial infections [4]. There are reports that AMPs can inhibit and eradicate biofilms to treat biofilm-related infections [5]. However, some disadvantages of AMPs, such as high toxicity and poor proteolytic stability, limit their clinical applications [6]. 
The introduction of unnatural amino acids has always been one of the most common strategies to improve the limitations of the AMPs mentioned above. Unnatural amino acids are not recognized by proteases, which increase the proteolysis resistance compared with natural amino acids [7]. Unnatural amino acids may increase the antimicrobial activity by balancing amphiphilicity with hydrophobicity [8] and may stabilize the structural conformation with intramolecular interactions to improve the salt tolerance [7]. For example, Wang et al. [9] described an increase in AMP salt resistance and activity after replacing tryptophan residues with $\beta$-naphthylalanine, which contains a hydrophobic naphthyl group on its side chain.

Feleucin-K3 (FLKLLKKLL-NH 2 ), a cationic nonapeptide composed of lysine (Lys or $\mathrm{K})$, phenylalanine (Phe or F) and leucine (Leu or L) residues, is a core sequence analog of an AMP secreted by the skin of Bombina orientalis [10]. It adopts a typical amphiphilic $\alpha$-helical structure and displays powerful antimicrobial activity against a range of bacteria, especially Pseudomonas aeruginosa (P. aeruginosa), which comprises a large proportion of the bacteria isolated in the clinic [11]. Hence, Feleucin-K3 is worthy of further study. Structure-activity relationship studies have demonstrated that the key site is the fourth residue, and the antimicrobial activity shows significant enhancement when it is replaced with alanine [11]. In addition, after $\alpha$-(4-pentenyl)-Ala, an unnatural hydrophobic amino acid, was introduced as the fourth residue, both the antimicrobial activity and stability improved greatly [12].

In this study, to maximize the antimicrobial activity and stability while minimizing the toxicity, the unnatural amino acid $\alpha$-(4-pentenyl)-Ala was further introduced into different positions of Feleucin-K3. Thus, Feleucin-K3 analogs with $\alpha$-(4-pentenyl)-Ala substitutions were designed and synthesized. Their antibacterial activity, antibiofilm activity, stability, toxicity and ability to induce AMR were comprehensively investigated. Among these analogs, K65 and K70 were screened, and their possible antimicrobial mechanisms were explored. Finally, the antibiofilm activities of the ideal short peptides K65 and K70 in vivo were determined through a biofilm infection model.

\section{Materials and Methods}

\subsection{Peptide Synthesis}

The Feleucin-K3 analogs in our study were synthesized by a stepwise solid-phase peptide synthesis (SPPS). The molecular weights of the analogs were confirmed by electrospray ionization mass spectrometry (ESI-MS; maXis 4G, Bruker Daltonics, Bremen, Germany). The crude peptides were purified by a preparative reversed-phase high-pressure liquid chromatography (RP-HPLC; Waters 600, Milford, MA, USA). Analytical RP-HPLC was used to determine the purity of the analogs, which should be more than $95 \%$.

\subsection{Strains and Animals}

All sensitive bacteria and multidrug-resistant bacteria were obtained from the Key Laboratory of New Drug Preclinical Research of Gansu Province, Lanzhou University, Lanzhou, China.

Female BALB/c mice were provided by the Medical Experimental Animal Center of Lanzhou University (SYXK GAN 2018-0002). The animal experiments strictly complied with the Guide for the Care and Use of Laboratory Animals of the National Institutes of Health and were approved by the Ethics Committee of Lanzhou University.

\subsection{Circular Dichroism (CD) Spectroscopy}

The $\alpha$-helical structures of the peptides were investigated using a J-810 spectrometer (Jasco, Tokyo, Japan). Peptides $(100 \mu \mathrm{g} / \mathrm{mL})$ were dissolved in 50\% trifluoroethanol (TFE) to mimic a hydrophobic membrane environment and 0.01-M PBS to mimic an aqueous environment [13]. The spectral wavelengths ranged from 190 to $260 \mathrm{~nm}$. The other parameters were as follows: $50-\mathrm{nm} / \mathrm{min}$ scanning rate, 1-nm bandwidth and a 1-s response. 


\subsection{Antimicrobial Activity and Salt Stability In Vitro}

The minimum inhibitory concentration (MIC) of the Feleucin-K3 analogs was tested by the broth microdilution method [11]. Sensitive bacteria and drug-resistant bacteria were diluted to $1 \times 10^{6} \mathrm{CFU} / \mathrm{mL}$, according to the McFarland standards. Bacterial suspension and peptide solutions $\left(8-128 \mu \mathrm{g} / \mathrm{mL}\right.$ ) were incubated at $37^{\circ} \mathrm{C}$ for $18 \mathrm{~h}$. The minimum concentration without obvious bacterial growth was the MIC of the peptides. The stability of the analogs in a physiological salt environment was also investigated. In brief, salt powder $(450-\mathrm{mM} \mathrm{NaCl})$ was dissolved in deionized water, and the following investigational steps were the same as those described before. The above steps were repeated several times, until the same value was obtained three times.

\subsection{Hemolytic Activity}

Mouse red blood cells (RBCs) were collected using the eyeball removal method to investigate the hemolytic activity of the Feleucin-K3 analogs [14]. Then, these analogs were incubated with the same volume of $8 \%$ RBC suspension for $1 \mathrm{~h} \mathrm{[11].} \mathrm{After} \mathrm{centrifugation}$ for $10 \mathrm{~min}, 100 \mu \mathrm{L}$ of supernatant was withdrawn, and the optical density at $490 \mathrm{~nm}$ was detected. The hemolysis rate of the cells treated with $0.1 \%$ Triton X-100 (Solarbio, Beijing, China) was used as a positive control, and PBS was used as a negative control.

\subsection{Serum Stability}

The Feleucin-K3 analogs (10 mM) were mixed with human serum (Biotop, Beijing, China) in a 1:4 ratio and incubated at $37^{\circ} \mathrm{C}$. At different times, cold acetonitrile was used to terminate the reaction. After centrifugation for $10 \mathrm{~min}$, the remaining peptides were monitored by RP-HPLC. The elution gradient was 5\%/95\% acetonitrile/water.

\subsection{In Vitro Antibiofilm Activity}

The antibiofilm activity of the peptides was determined according to the previously described methods [15]. Strains (final concentration of $5 \times 10^{5} \mathrm{CFU} / \mathrm{mL}$ ) and peptides $(4-128 \mu \mathrm{g} / \mathrm{mL})$ were incubated for $24 \mathrm{~h}$ at $37^{\circ} \mathrm{C}$. Biofilm cells were cleaned with 0.01-M PBS and fixed with methanol. Crystal violet (0.1\%, HopeBiol, Qingdao, China) was used to stain the biofilm cells for $10 \mathrm{~min}$. After washing with water, $95 \%$ ethanol was finally added, and the optical density at $595 \mathrm{~nm}$ was measured with a microplate reader (Flex Station 3; Laguna Hills, CA, USA).

\subsection{Confocal Laser Scanning Fluorescence Microscopy (CLSM)}

The antibiofilm activity of the Feleucin-K3 analogs was determined using a LIVE/DEAD Biofilm Viability Kit and concanavalin A conjugates (Invitrogen, Waltham, MA, USA). In brief, MRSA ATCC $33591\left(5 \times 10^{5} \mathrm{CFU} / \mathrm{mL}\right)$ and an equal volume of peptides (final concentration $4 \mu \mathrm{g} / \mathrm{mL}$ or $8 \mu \mathrm{g} / \mathrm{mL}$ ) were incubated in culture dishes. Propidium iodide (PI) at the concentration of $6 \mu \mathrm{g} / \mathrm{mL}$ and the same concentration of SYTO9 were premixed and added to the dish [16]. After incubation for $30 \mathrm{~min}$, CLSM (Zeiss LSM 710 Meta; Karl, Germany) was used to visually observe the results. The three-dimensional structure images were obtained by Z-stack mode. In addition, the exopolysaccharide matrix secreted by the biofilm cells was stained with concanavalin A conjugates $(40 \mu \mathrm{g} / \mathrm{mL})$ and observed according to the above method.

\subsection{Scanning Electron Microscopy (SEM)}

MRSA ATCC $33591\left(5 \times 10^{5} \mathrm{CFU} / \mathrm{mL}\right)$ and peptides (low concentration of $4 \mu \mathrm{g} / \mathrm{mL}$ or high concentration of $8 \mu \mathrm{g} / \mathrm{mL}$ ) were incubated for $24 \mathrm{~h}$. Then, cell climbing sheets with biofilms were gradually processed according to the following steps: washing with PBS several times, fixing with $2.5 \%$ glutaraldehyde overnight at $4{ }^{\circ} \mathrm{C}$, dehydration in ethanol for $10 \mathrm{~min}$, freeze-drying for $6 \mathrm{~h}$, coating in gold for $30 \mathrm{~s}$ and, finally, observing with an Apreo S (Thermo Fisher Scientific, Waltham, MA, USA) [17]. In addition, the morphological changes in the MRSA treated with peptides were also observed using the Apreo S. MRSA 
ATCC $33591\left(1 \times 10^{9} \mathrm{CFU} / \mathrm{mL}\right)$ was incubated with analogs $(2 \times$ MIC or $4 \times \mathrm{MIC})$ for $30 \mathrm{~min}$ or $120 \mathrm{~min}$. The cells were processed and observed as previously described.

\subsection{Time-Killing Assay}

The rapid bactericidal ability of the Feleucin-K3 analogs was evaluated by time-killing kinetics [18]. K65 and K70 were diluted to different concentrations ranging from $1 \times$ to $4 \times$ MIC. Bacteria $\left(5 \times 10^{5} \mathrm{CFU} / \mathrm{mL}\right)$ were mixed with $\mathrm{K} 65$ and $\mathrm{K} 70$. After incubation in a 1:1 ratio, the number of bacteria at different times was determined by plating on Mueller-Hinton agar plates.

\subsection{Resistance Development Assay}

Serial passage and MIC determination were used to explore whether the bacteria developed drug resistance. On the first day, the MICs of the peptides were determined as described above. The next day, the bacterial suspension of sub-MIC concentration was cultivated to the mid-log phase. The MICs of the peptides were detected again, and this process was repeated for 20 days. The MICs of the antibiotics, including amoxicillin (AML), ceftazidime (CAZ) and imipenem, were also determined as controls.

\subsection{Lipopolysaccharide (LPS)/Lipoteichoic Acid (LTA) Competitive Inhibition Assay}

An equal volume of LPS/LTA $(2-1024 \mu \mathrm{g} / \mathrm{mL})$ was mixed with K65 or K70 $(2 \times$ MIC) [19]. After incubation for $1 \mathrm{~h}$, the bacterial suspension $\left(5 \times 10^{5} \mathrm{CFU} / \mathrm{mL}\right)$ was added, followed by coincubation for another $2 \mathrm{~h}$. Finally, the samples were properly diluted, and the number of colonies was recorded by plating on Mueller-Hinton agar plates.

\subsection{Outer Membrane Permeabilization}

The bacterial outer membrane permeabilization induced by the Feleucin-K3 analogs was determined using the fluorescent dye $N$-phenyl-1-naphthylamine (NPN; I\&K Scientific, Beijing, China) [20]. In brief, mid-log-phase bacteria were centrifuged and resuspended to an $\mathrm{OD}_{600}=0.5$ in HEPES buffer. Different concentrations of K65 and K70 were added first, followed by the addition of NPN $(40 \mu \mathrm{M})$ and the prepared bacterial suspension. The fluorescence changes within 20 min were monitored using a microplate reader.

\subsection{Cytoplasmic Membrane Depolarization}

Bacterial cytoplasmic membrane depolarization was investigated using 3,3'-dipropylthiadicarbocyanine iodide ( $\mathrm{DiSC}_{3}$ (5); Sigma Aldrich, St Louis, MO, USA) [20]. In short, a bacterial suspension $\left(\mathrm{OD}_{600}=0.1\right)$ was resuspended in HEPES buffer containing 5 -mM HEPES, 20-mM glucose and 100-mM KCl. DiSC ${ }_{3}(5)(4 \mu \mathrm{M})$ and the bacteria were incubated at $37{ }^{\circ} \mathrm{C}$ for $1 \mathrm{~h}$. Then, this mixture and peptides were added to a 96-well plate. The fluorescence was monitored in real time using a microplate reader.

\subsection{PI Uptake Assay}

A PI uptake assay was used to explore the membrane integrity after treatment with the peptides [20]. Mid-log-phase S. aureus and Acinetobacter baumannii (A. baumannii) were diluted to $1 \times 10^{8} \mathrm{CFU} / \mathrm{mL}$. Then, the bacteria were treated with K65 and K70 $(4 \times \mathrm{MIC})$ for $30 \mathrm{~min}$. PI dye $(1 \mathrm{mg} / \mathrm{mL})$ was added, followed by incubation for another $15 \mathrm{~min}$. The samples were observed by CLSM.

\subsection{DNA-Binding Affinity Assay}

Bacterial genomic DNA was extracted using a Bacterial Genomic DNA Extraction Kit (TIANGEN, Beijing, China). Approximately $400 \mathrm{ng}$ of genomic DNA was mixed with the peptides $(1 \times$ to $8 \times \mathrm{MIC})$ for $30 \mathrm{~min}$. The mixtures were subjected to agarose gel electrophoresis with a concentration of agarose of $1 \%$. The DNA bands were observed by ultraviolet (UV) illumination with an Image Quant 300 gel documentation system (GE Healthcare, Marlborough, MA, USA). 


\subsection{In Vivo Antibiofilm Activity}

Female BALB/c (18-20 g) mice were fed adaptively for one week, and then, a biofilm infection model was constructed as previously described [21]. In brief, an incision (approximately $1 \mathrm{~cm}$ ) was made on the dorsal region of the mice, and a $1-\mathrm{cm}$ sterile urinary catheter was placed in the incision. Sterile surgical threads were used to suture the incision. For bacterial preparation, S. aureus ATCC 25923 and MRSA ATCC 33591 were diluted to $1 \times 10^{6} \mathrm{CFU} / \mathrm{mL}$. One hundred microliters of bacterial suspension were injected into the catheter. Mice in groups of ten were injected with $100 \mu \mathrm{L}$ of PBS as a negative control. One hundred microliters of AML ( $1 \mu \mathrm{g} / \mathrm{mL}$ for $S$. aureus and $64 \mu \mathrm{g} / \mathrm{mL}$ for MRSA) were set as the antibiotic control, and $100 \mu \mathrm{L}$ of peptides $(16 \mu \mathrm{g} / \mathrm{mL})$ were set as the experimental group. Mice were treated twice a day for three days. Finally, the catheters were placed in $1 \mathrm{~mL}$ of sterile PBS. After sonication for $20 \mathrm{~min}$, the number of colonies was recorded after proper dilution and plating on Mueller-Hinton agar plates.

\subsection{Statistical Analysis}

All experiments were repeated at least three times, and the statistical analysis was performed using GraphPad Prism 8.0 software (San Diego, CA, USA).

\section{Results}

\subsection{Design and Characterization of the Peptides}

The synthetic Feleucin-K3 analogs were mainly modified by $\alpha$-(4-pentenyl)-Ala to improve the antimicrobial activity, stability and decrease the hemolytic activity. Sequence truncation is an effective strategy to obtain shorter peptides while maintaining the activity [22]. Moreover, the first and fourth residues, Phe and Leu, were confirmed at key positions affecting the structure and antimicrobial activity of Feleucin-K3 in our previous study [11], and we designed and synthesized some analogs containing eight amino acid residues. The masses of the peptides were characterized by ESI-MS and were shown in Table 1 . The purity $(>95 \%)$ and retention time $\left(T_{R}\right)$ were obtained by RP-HPLC. The $T_{R}$ reflected the hydrophobicity, and the $T_{R}$ values were listed from long to short (from strong hydrophobicity to weak) in the following order: K63 > K71 > K69 > K68 > K67 > K70 > K64 $>\mathrm{K} 65>\mathrm{K} 66$.

Table 1. The main physicochemical properties of the Feleucin-K3 analogs.

\begin{tabular}{|c|c|c|c|c|c|c|c|c|}
\hline Peptides. & Sequence $^{a}$ & $\begin{array}{l}\text { Mass } \\
\text { (Da) }^{b}\end{array}$ & $\begin{array}{c}\text { Number of } \\
\text { Amino } \\
\text { Acids }\end{array}$ & $\begin{array}{l}\text { Net } \\
\text { Charge }\end{array}$ & $T_{R}(\operatorname{Min})^{c}$ & $\begin{array}{l}\alpha-\text { Helix }^{(\%)} \\
\text { PBS }^{\mathrm{d}}\end{array}$ & $\begin{array}{c}\alpha \text {-Helix (\%) } \\
\text { TFE }^{d}\end{array}$ & Purity (\%) ${ }^{c}$ \\
\hline Feleucin-K63 & LKLLKKLL-NH $_{2}$ & 967.7 & 8 & +4 & 23.738 & 4.600 & 14.970 & 96.070 \\
\hline Feleucin-K64 & $\begin{array}{l}\text { LK } \alpha \text {-(4-pentenyl)- } \\
\text { AlaLKKLL-NH } 2\end{array}$ & 993.8 & 8 & +4 & 17.768 & 3.330 & 2.900 & 100.000 \\
\hline Feleucin-K65 & $\begin{array}{c}\alpha \text {-(4-pentenyl)- } \\
\text { AlaLKLLKKLL-NH } 2\end{array}$ & 1106.8 & 9 & +4 & 17.762 & 2.920 & 5.120 & 98.900 \\
\hline Feleucin-K66 & $\begin{array}{c}\alpha-(4-p e n t e n y l)- \\
\text { AlaLKAKKLL-NH }\end{array}$ & 951.7 & 8 & +4 & 14.450 & 3.140 & 5.050 & 96.250 \\
\hline Feleucin-K67 & $\begin{array}{l}\text { F } \alpha \text {-(4-pentenyl)- } \\
\text { AlaKLLKKLL-NH } 2\end{array}$ & 1140.8 & 9 & +4 & 18.086 & 3.620 & 18.610 & 98.450 \\
\hline Feleucin-K68 & $\begin{array}{l}\text { FLKL } \alpha \text {-(4-pentenyl)- } \\
\text { AlaKKLL-NH }\end{array}$ & 1140.8 & 9 & +4 & 18.466 & 2.930 & 19.640 & 100.000 \\
\hline Feleucin-K69 & $\begin{array}{c}\text { FLKLLKK } \alpha-(4- \\
\text { pentenyl)-AlaL-NH }\end{array}$ & 1140.8 & 9 & +4 & 18.635 & 2.990 & 7.140 & 100.000 \\
\hline Feleucin-K70 & $\begin{array}{l}\text { FLKLLKKL } \alpha-(4- \\
\text { pentenyl)-Ala-NH }\end{array}$ & 1140.8 & 9 & +4 & 17.942 & 3.070 & 15.620 & 100.000 \\
\hline Feleucin-K71 & $\begin{array}{l}\text { FLKLL } \alpha-(4-\text { pentenyl)- } \\
\text { AlaKLL-NH } \\
\end{array}$ & 1125.8 & 9 & +3 & 20.493 & 1.870 & 5.240 & 100.000 \\
\hline
\end{tabular}

${ }^{a}$ Red indicates the substitution site. ${ }^{b}$ Mass was measured by ESI-MS. ${ }^{c} T_{R}(\min )$ and purity were measured by RP-HPLC. ${ }^{d} \alpha$-helix (\%) was measured by CD spectroscopy. 
The CD spectra were showed in Figure 1. In 0.01-M PBS, the secondary structures of the Feleucin-K3 analogs had no regularity. The $\alpha$-helical content was calculated using the K2D3 algorithm (http:/ / cbdm-01.zdv.uni-mainz.de/ andrade/k2d3/, accessed on 23 May 2020). In $50 \%$ TFE, K63, K67, K68 and K70 had increased $\alpha$-helical contents compared to PBS. These analogs displayed two minimum peaks at 208 and $220 \mathrm{~nm}$, which were consistent with the $\alpha$-helical structure. It is worth nothing that the $\alpha$-helical contents of these synthetic analogs decreased compared with Feleucin-K3, indicating that the introduced unnatural amino acid might cause a decrease in amphipathic conformation.

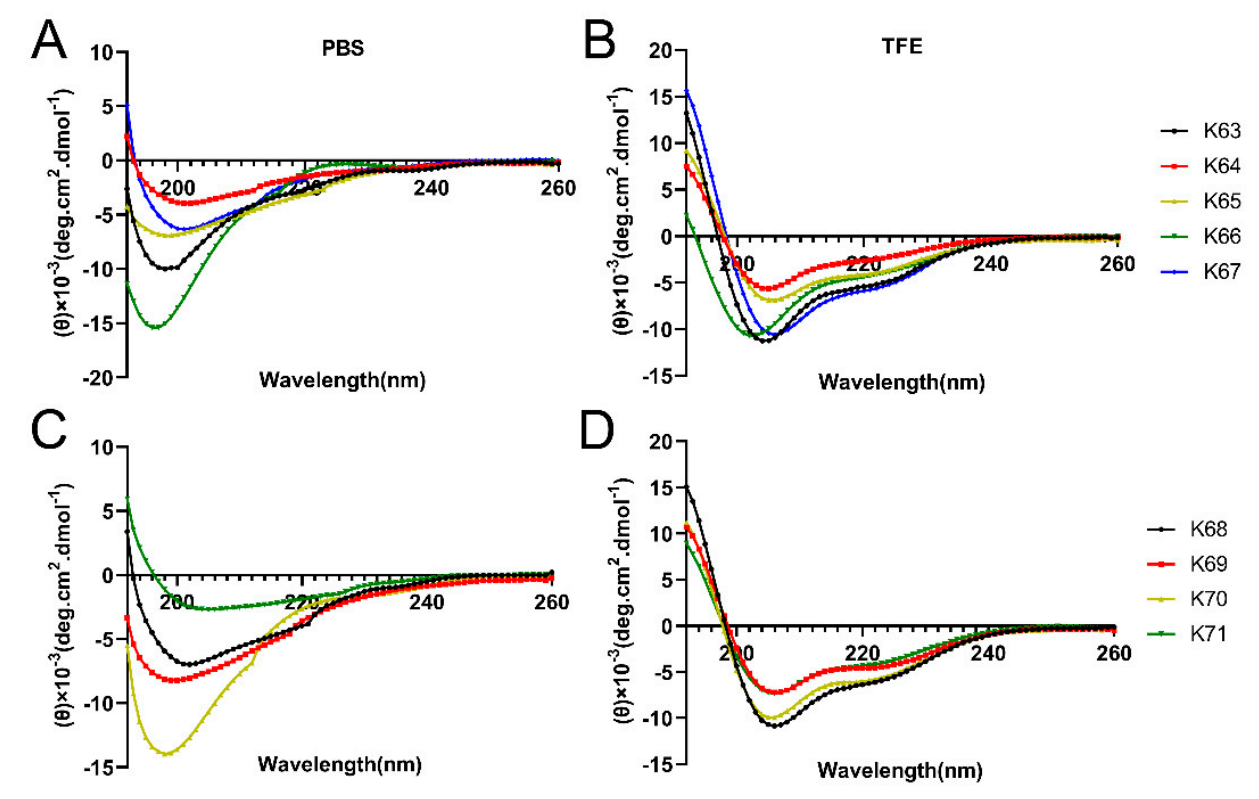

Figure 1. The secondary structure of Feleucin-K3 analogs in (A,C) 0.01-M PBS (pH 7.4) and (B,D) 50\% TFE. The mean residue ellipticity was plotted against the wavelength.

\subsection{Antimicrobial Activity In Vitro}

As shown in Table 2, the analogs K65, K67, K68, K69, K70 and K71, with $\alpha$-(4pentenyl)-Ala replacements, had enhanced antimicrobial activity against the standard strains, with MICs ranging from 4 to $8 \mu \mathrm{g} / \mathrm{mL}$. Moreover, for MRSA and A. baumannii isolated from the clinic, the antimicrobial activity of these peptides was significant in comparison with the antibiotics tested (Tables 3 and 4). The MICs of the Feleucin-K3 analogs were $4-8 \mu \mathrm{g} / \mathrm{mL}$, which were much lower than the MICs of AML against MRSA (up to $128 \mu \mathrm{g} / \mathrm{mL}$ ) [16]. It was also found in previous studies that the MICs of imipenem against multidrug-resistant $A$. baumannii were as high as $64 \mu \mathrm{g} / \mathrm{mL}$, indicating that the antimicrobial activity was significantly weaker than that of the designed Feleucin-K3 analogs [16]. Notably, these Feleucin-K3 analogs had more powerful antimicrobial activities than Magainin 2, which has been studied in greater detail. The antimicrobial activity of K63, K64 and K66 containing eight residues was unsatisfactory, implying that the first residue (Phe) was critical to the structural integrity and antimicrobial activity. 
Table 2. MICs of the Feleucin-K3 analogs against the standard strains.

\begin{tabular}{ccccc}
\hline \multirow{2}{*}{ Peptides } & \multicolumn{4}{c}{ MIC $(\mu \mathrm{g} / \mathrm{mL})$} \\
\cline { 2 - 5 } & $\begin{array}{c}\text { E. coli } \\
\text { ATCC 25922 }\end{array}$ & $\begin{array}{c}\text { S. aureus } \\
\text { ATCC 25923 }\end{array}$ & $\begin{array}{c}\text { P. aeruginosa } \\
\text { ATCC 27853 }\end{array}$ & $\begin{array}{c}\text { A. baumannii } \\
\text { ATCC 19606 }\end{array}$ \\
\hline Feleucin-K63 & $>128$ & $>128$ & 64 & $>128$ \\
Feleucin-K64 & 16 & 16 & 4 & 64 \\
Feleucin-K65 & 8 & 8 & 8 & 4 \\
Feleucin-K66 & $>128$ & $>128$ & $>128$ & $>128$ \\
Feleucin-K67 & 8 & 4 & 8 & 4 \\
Feleucin-K68 & 8 & 4 & 8 & 4 \\
Feleucin-K69 & 8 & 4 & 8 & 8 \\
Feleucin-K70 & 8 & 8 & 8 & 4 \\
Feleucin-K71 & 16 & 4 & 8 & 16 \\
Magainin 2 & 64 & $>256$ & 256 & 8 \\
\hline
\end{tabular}

Table 3. MICs of the Feleucin-K3 and analogs against the multidrug-resistant S. aureus.

\begin{tabular}{cccccccc}
\hline & \multicolumn{7}{c}{ MIC $(\mu \mathrm{g} / \mathrm{mL})$} \\
\hline MRSA & K3 & K65 & K67 & K68 & K69 & K70 & K71 \\
\hline MRSA ATCC 33591 & 8 & 4 & 4 & 4 & 4 & 8 & 4 \\
MRSA 48 & 8 & 4 & 4 & 4 & 4 & 8 & 4 \\
MRSA 54 & 8 & 4 & 4 & 4 & 4 & 8 & 4 \\
MRSA 936 & 8 & 4 & 4 & 4 & 4 & 8 & 4 \\
MRSA 52 & 8 & 4 & 4 & 8 & 4 & 8 & 4 \\
MRSA 74 & 8 & 4 & 4 & 4 & 8 & 8 & 4 \\
MRSA 23 & 8 & 4 & 4 & 4 & 4 & 8 & 4 \\
MRSA 75 & 8 & 4 & 4 & 4 & 4 & 8 & 4 \\
MRSA 113 & 8 & 8 & 4 & 4 & 4 & 8 & 4 \\
MRSA 51 & 8 & 8 & 4 & 4 & 4 & 8 & 4 \\
MRSA 71 & 8 & 4 & 4 & 8 & 4 & 8 & 4 \\
S. aureus 794 & 16 & 8 & 8 & 8 & 8 & 8 & 16 \\
S. aureus 725 & 8 & 4 & 4 & 4 & 4 & 8 & 4 \\
\hline
\end{tabular}

Table 4. MICs of the Feleucin-K3 and analogs against the multidrug-resistant $A$. baumannii.

\begin{tabular}{cccccccc}
\hline & \multicolumn{7}{c}{ MIC $(\boldsymbol{\mu g} / \mathbf{m L})$} \\
\hline A. baumannii & K3 & K65 & K67 & K68 & K69 & K70 & K71 \\
\hline A. baumannii 9828 & 16 & 4 & 4 & 4 & 8 & 8 & 16 \\
A. baumannii 9840 & 8 & 4 & 4 & 4 & 8 & 8 & 8 \\
A. baumannii 9896 & 8 & 4 & 4 & 4 & 8 & 4 & 8 \\
A. baumannii 91152 & 8 & 4 & 4 & 4 & 8 & 8 & 16 \\
A. baumannii 98110 & 8 & 4 & 4 & 4 & 8 & 8 & 16 \\
A. baumannii 92359 & 8 & 4 & 4 & 4 & 4 & 8 & 16 \\
A. baumannii 97830 & 8 & 4 & 4 & 4 & 8 & 8 & 32 \\
A. baumannii 9234 & 8 & 4 & 4 & 4 & 8 & 8 & 8 \\
A. baumannii 5444 & 8 & 4 & 4 & 4 & 8 & 8 & 8 \\
A. baumannii 9236 & 16 & 4 & 4 & 4 & 8 & 8 & 16 \\
A. baumannii 91869 & 8 & 4 & 4 & 4 & 8 & 8 & 8 \\
A. baumannii 91199 & 8 & 4 & 4 & 4 & 8 & 8 & 16 \\
A. baumannii 9336 & 8 & 4 & 4 & 4 & 8 & 8 & 8 \\
A. baumannii 91810 & 8 & 4 & 4 & 4 & 8 & 8 & 16 \\
A. baumannii 822144 & 8 & 8 & 4 & 4 & 8 & 8 & 16 \\
A. baumannii 91944 & 8 & 4 & 4 & 4 & 8 & 8 & 16 \\
A. baumannii 91105 & 8 & 4 & 4 & 4 & 8 & 4 & 8 \\
A. baumannii 51243 & 8 & 4 & 4 & 4 & 8 & 8 & 32 \\
A. baumannii 8309 & 8 & 4 & 4 & 4 & 8 & 8 & 8 \\
A. baumannii 9331 & 16 & 8 & 8 & 8 & 8 & 16 & 64 \\
\hline
\end{tabular}




\subsection{Salt Stability}

Generally, in the presence of physiological salt conditions, the antimicrobial activity is affected. Herein, the stability of the Feleucin- $\mathrm{K} 3$ analogs in $150-\mathrm{mM} \mathrm{NaCl}$ was determined, and the results are shown in Table 5. In 150-mM NaCl, the antimicrobial activity of K68 against all tested bacteria was not affected by monovalent ions $\left(\mathrm{Na}^{+}\right)$, and its MICs did not increase. The MICs of the other peptides increased slightly by approximately two- to four-fold, but the activities of these analogs remained desirable. Notably, the antimicrobial activity of all analogs against MRSA ATCC 33591 was still powerful under the physiological salt conditions, with the MICs ranging from 4 to $8 \mu \mathrm{g} / \mathrm{mL}$.

Table 5. Salt stability of the Feleucin-K3 analogs.

\begin{tabular}{|c|c|c|c|c|c|c|c|c|c|c|}
\hline \multirow{2}{*}{ Peptides } & \multicolumn{2}{|c|}{$\begin{array}{c}E . \text { coli } \\
\text { ATCC } 25922\end{array}$} & \multicolumn{2}{|c|}{$\begin{array}{c}\text { S. aureus } \\
\text { ATCC } 25923\end{array}$} & \multicolumn{2}{|c|}{$\begin{array}{l}\text { P. aeruginosa } \\
\text { ATCC } 27853\end{array}$} & \multicolumn{2}{|c|}{$\begin{array}{l}\text { A. baumannii } \\
\text { ATCC } 19606\end{array}$} & \multicolumn{2}{|c|}{$\begin{array}{c}\text { MRSA } \\
\text { ATCC } 33591\end{array}$} \\
\hline & $\begin{array}{c}\text { 150-mM } \\
\mathrm{NaCl}\end{array}$ & $\begin{array}{c}\text { Fold } \\
\text { Change }\end{array}$ & $\begin{array}{c}\text { 150-mM } \\
\mathrm{NaCl}\end{array}$ & $\begin{array}{c}\text { Fold } \\
\text { Change }\end{array}$ & $\begin{array}{c}\text { 150-mM } \\
\mathrm{NaCl}\end{array}$ & $\begin{array}{c}\text { Fold } \\
\text { Change }\end{array}$ & $\begin{array}{c}\text { 150-mM } \\
\mathrm{NaCl}\end{array}$ & $\begin{array}{c}\text { Fold } \\
\text { Change }\end{array}$ & $\begin{array}{c}\text { 150-mM } \\
\mathrm{NaCl}\end{array}$ & $\begin{array}{c}\text { Fold } \\
\text { Change }\end{array}$ \\
\hline K65 & 32 & 4 & 8 & 2 & 32 & 4 & 16 & 4 & 4 & 1 \\
\hline K67 & 16 & 2 & 4 & 1 & 8 & 1 & 8 & 2 & 4 & 1 \\
\hline K68 & 8 & 1 & 4 & 1 & 8 & 1 & 4 & 1 & 4 & 1 \\
\hline K69 & 16 & 2 & 8 & 2 & 16 & 2 & 16 & 2 & 8 & 2 \\
\hline K70 & 32 & 4 & 16 & 2 & 8 & 1 & 16 & 2 & 8 & 1 \\
\hline K71 & 16 & 1 & 4 & 1 & 16 & 2 & 8 & 2 & 4 & 1 \\
\hline
\end{tabular}

\subsection{Hemolytic Activity}

The hemolytic activities of the Feleucin-K3 analogs showed a significant difference compared with the parent Feleucin-K3 (Figure 2). In our previous study, Feleucin-K3 showed toxicities at high concentrations. The hemolytic rate was more than $40 \%$ at the concentration of $256 \mu \mathrm{g} / \mathrm{mL}$ [11]. K65 and K70, the analogs with $\alpha$-(4-pentenyl)-Ala at the $\mathrm{N}$-terminus and C-terminus, respectively, showed low hemolytic activity. Notably, the hemolysis rates of $\mathrm{K} 65$ were $9.08 \%$ and $31.6 \%$ at concentrations of $64 \mu \mathrm{g} / \mathrm{mL}$ and $128 \mu \mathrm{g} / \mathrm{mL}$, respectively. The hemolysis rates of $\mathrm{K} 70$ were less than $1 \%$, even at the maximum concentration $(128 \mu \mathrm{g} / \mathrm{mL})$. The hemolytic activity of K70 decreased significantly compared with Feleucin-K3. The other analogs showed negligible hemolytic activity at their antimicrobial concentrations but, unfortunately, showed high hemolysis at high concentrations.

A

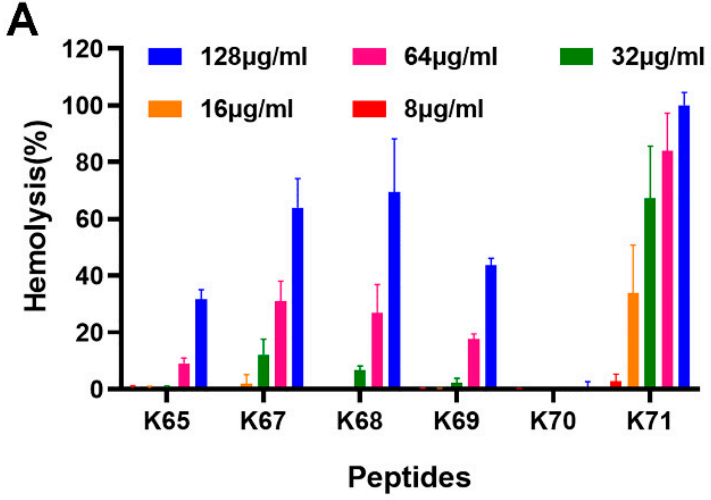

B

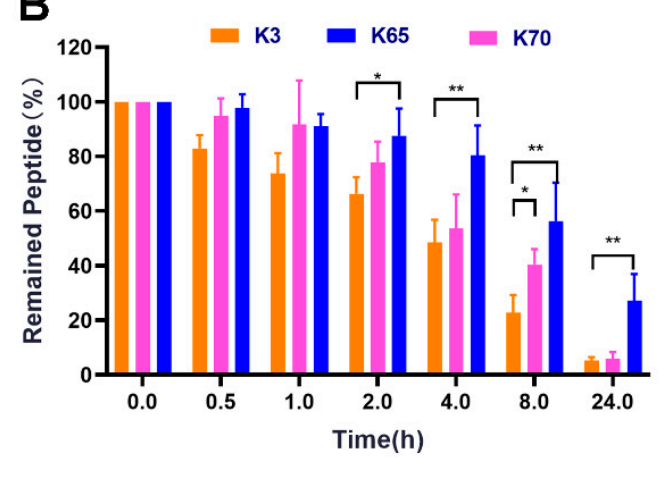

Figure 2. (A) Hemolytic activity of Feleucin-K3 analogs against mouse RBCs. The effect of $2 \%$ Triton X-100 on destroying the RBCs was regarded as a positive control and PBS as a negative control. (B) The serum stability of Feleucin-K3 and its analogs. The remaining peptides were determined using RP-HPLC after incubation with human serum for different times. The symbols represent the means \pm standard deviations from triplicate determinations. 


\subsection{Serum Stability}

Human serum digests realistically imitate the actual situation in organisms. Herein, the stabilities were evaluated for the Feleucin-K3 analogs by determining the amounts of remaining peptides after different incubation times. As shown in Figure 2, approximately $80 \%$ of Feleucin-K3 was degraded after incubation with the human serum for $8 \mathrm{~h}$. After $24 \mathrm{~h}$, the content of Feleucin-K3 was only 5.83\%, implying that it was completely degraded. In contrast, the retention rate of $\mathrm{K} 65$ was $56.4 \%$ and $27.3 \%$ after $8 \mathrm{~h}$ and $24 \mathrm{~h}$, respectively. K70 had different levels of degradation after incubation for different times. The statistically significant differences could be determined compared with Feleucin-K3 when they were incubated with the serum for $8 \mathrm{~h}$. The serum stabilities of K65 showed statistically significant differences compared with that of Feleucin-K3 at 2 h, 4 h, 8 h and $24 \mathrm{~h}$.

\subsection{Time-Kill Kinetic Curves}

K65 and K70 were chosen to test their bactericidal activity after different treatment times. In our study, the bactericidal effects of K65 and K70 were rapid and related to both the time and concentration (Figure 3). For S. aureus and E. coli, K70 $(4 \times \mathrm{MIC})$ killed the bacteria in $30 \mathrm{~min}$ or $1 \mathrm{~h}$, which was comparable to K65. However, K65 at high concentrations had a more powerful short-term killing effect against $P$. aeruginosa than K70. P. aeruginosa could not be detected after 15 min of treatment with K65. Moreover, the bactericidal activity of K70 against $A$. baumannii was extremely significant. No bacteria were detected after treatment for 5 min with $4 \times$ MIC of K70.

A
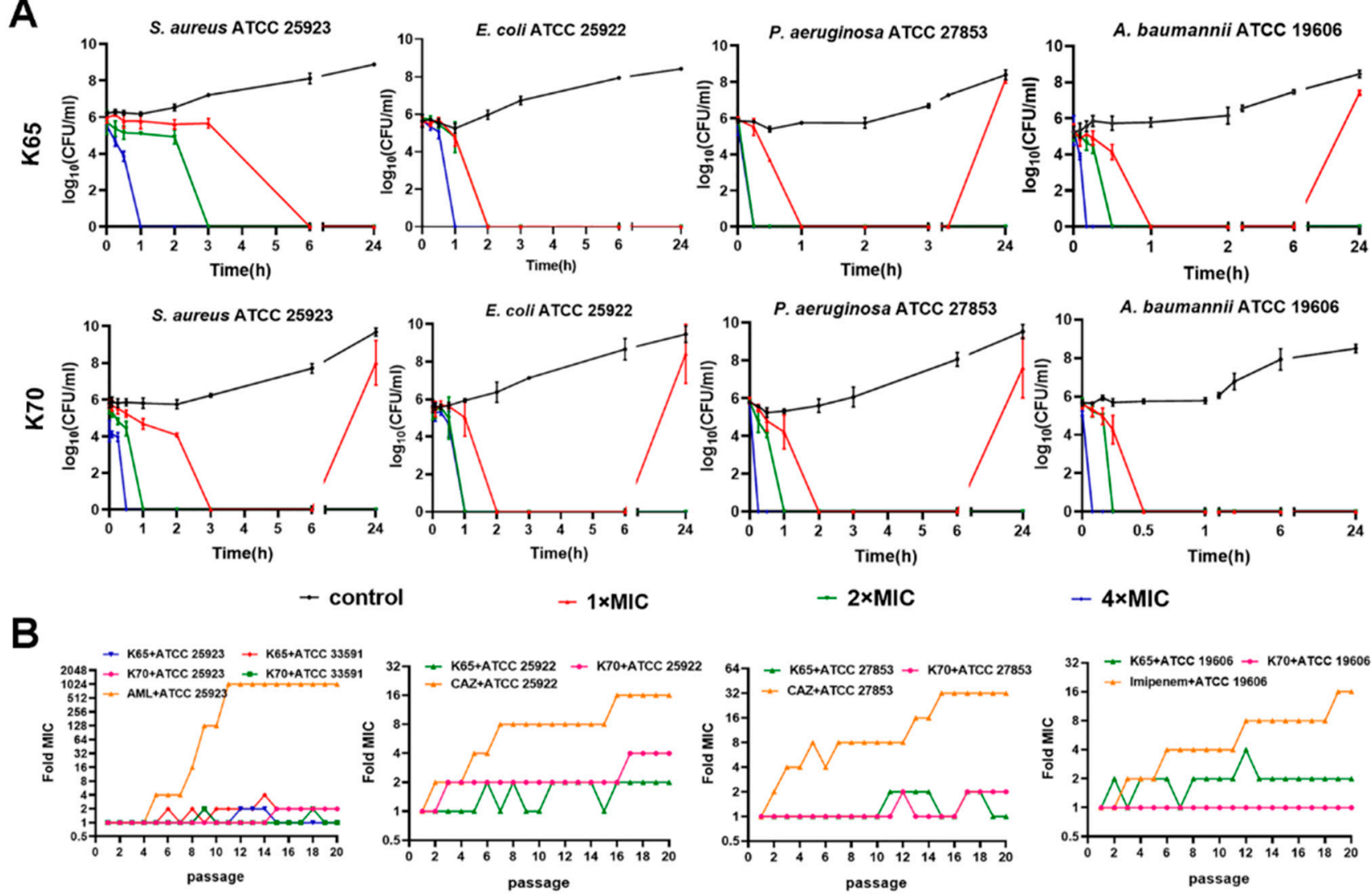

Figure 3. (A) The time-kill kinetics of K65 and K70 against S. aureus ATCC 25923, E. coli ATCC 25922, P. aeruginosa ATCC 27853 and A. baumannii ATCC 19606. (B) Resistance induced by K65 and K70 by the sequential passaging method. The fold changes of the MICs of AML, CAZ and Imipenem were also recorded to detect the resistance. 


\subsection{Resistance Development Assay}

The sequential passaging method was used to determine the bacterial resistance development induced by K65 and K70. As shown in Figure 3, the MICs of K65 and K70 against the standard strains (including S. aureus, A. baumannii, E. coli and P. aeruginosa) and drug-resistant MRSA displayed only slight fluctuations, showing a one- to four-fold increase after 20 passages. In sharp contrast, the antibiotic resistance increased dramatically. AML-resistant mutants were produced as early as passage 5, and the MICs increased by a maximum of 1024-fold against S. aureus. The MICs with CAZ increased 32-fold and 16-fold against $P$. aeruginosa and E. coli, respectively. In addition, the MICs of imipenem against A. baumannii increased by a maximum of 16-fold. These results indicated that K65 and K70 showed significant advantages by posing as a low risk for resistance development in comparison with the antibiotics tested.

\subsection{Biofilm Inhibition Activity In Vitro}

The antibiofilm activities of the peptides against both sensitive bacteria and MRSA were evaluated, and the results are shown in Figure 4 and Table 6 . K65 and K70 $(0.5 \times$ to $4 \times$ MIC) significantly inhibited the bacterial biofilm formation. Notably, both K65 and K70 displayed perfect MRSA biofilm inhibition activity at the low concentration of $8 \mu \mathrm{g} / \mathrm{mL}$. Therefore, their antibiofilm effects against MRSA were further explored using CLSM (Figures 5 and 6) and SEM (Figure 7).

Table 6. Antibiofilm activity.

\begin{tabular}{ccccccc}
\hline \multirow{2}{*}{ Strains } & \multicolumn{3}{c}{ K65 $(\boldsymbol{\mu g} / \mathbf{m L})$} & \multicolumn{3}{c}{ K70 $(\boldsymbol{\mu g} / \mathbf{m L})$} \\
\cline { 2 - 7 } & MIC & MBIC $_{\mathbf{5 0}}$ & MBIC $_{\mathbf{9 0}}$ & MIC & MBIC $_{\mathbf{5 0}}$ & MBIC $_{\mathbf{9 0}}$ \\
\hline S. aureus ATCC 25923 & 8 & 8 & 16 & 8 & 4 & 8 \\
MRSA ATCC 33591 & 4 & 8 & 8 & 8 & 4 & 8 \\
E. coli ATCC 25922 & 8 & 16 & 32 & 8 & 8 & 32 \\
A. baumannii ATCC 19606 & 4 & 8 & 8 & 8 & 8 & 16 \\
P.aeruginosa ATCC 27853 & 8 & 8 & 16 & 8 & 8 & 16 \\
\hline
\end{tabular}

\subsubsection{CLSM}

The ability of K65 and K70 to inhibit the MRSA biofilm formation was assessed by CLSM. As shown in Figure 5, almost all MRSA biofilm cells without peptide treatment were stained green by SYTO9, implying that mature and thick biofilms developed in the control group. However, K65 and K70 significantly inhibited the MRSA biofilm formation. In the low-concentration groups, there were numerous dead biofilm cells. In the highconcentration groups, only sporadic fluorescence was observed in the field of vision. In the 3D images, the thicknesses of the biofilms exposed to K65 $(40 \mu \mathrm{m}$ at $4 \mu \mathrm{g} / \mathrm{m}$ and $10 \mu \mathrm{m}$ at $8 \mu \mathrm{g} / \mathrm{mL})$ and $\mathrm{K} 70(30 \mu \mathrm{m}$ at $4 \mu \mathrm{g} / \mathrm{m}$ and $20 \mu \mathrm{m}$ at $8 \mu \mathrm{g} / \mathrm{mL})$ decreased tremendously compared with the untreated biofilm $(60 \mu \mathrm{m})$.

In addition, exopolysaccharides are one of the main extracellular polymeric substance (EPS) components, which are beneficial for maintaining a mature biofilm structure. In our study, K65 and K70 showed a strong ability to inhibit the formation and accumulation of exopolysaccharides (Figure 6). The 3D images showed that the thicknesses of the biofilms exposed to $\mathrm{K} 65(30 \mu \mathrm{m}$ at $4 \mu \mathrm{g} / \mathrm{mL}$ and $20 \mu \mathrm{m}$ at $8 \mu \mathrm{g} / \mathrm{mL})$ or $\mathrm{K} 70(30 \mu \mathrm{m}$ at $4 \mu \mathrm{g} / \mathrm{mL}$ and $20 \mu \mathrm{m}$ at $8 \mu \mathrm{g} / \mathrm{mL}$ ) decreased significantly in comparison with the control group ( $80 \mu \mathrm{m})$. 
A

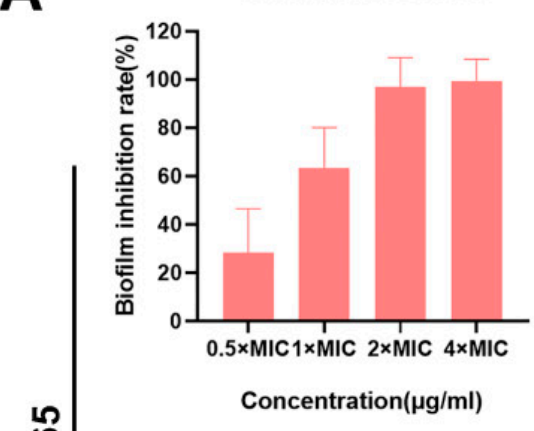

MRSA ATCC 33591

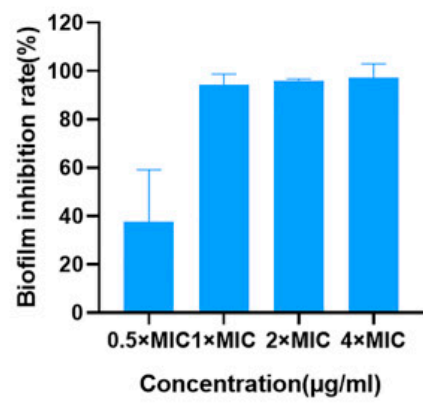

E. coli ATCC 25922

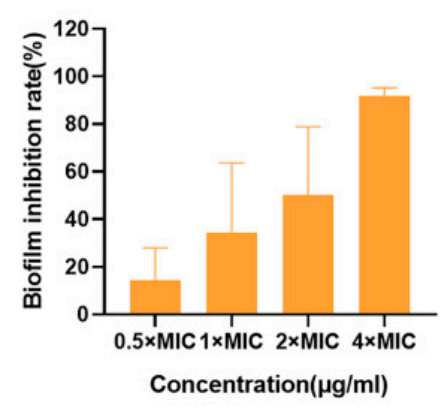

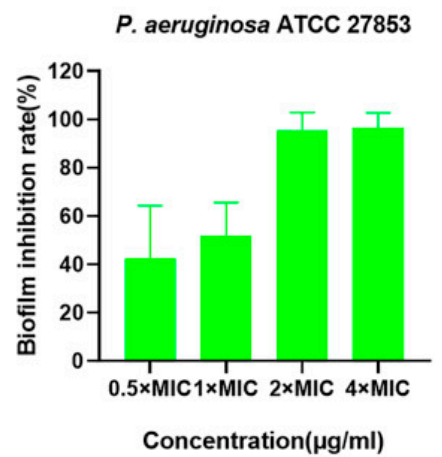

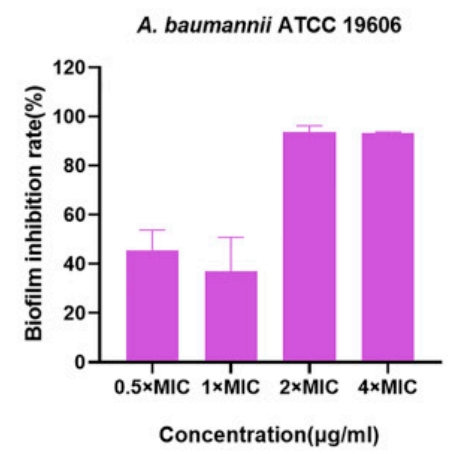

B
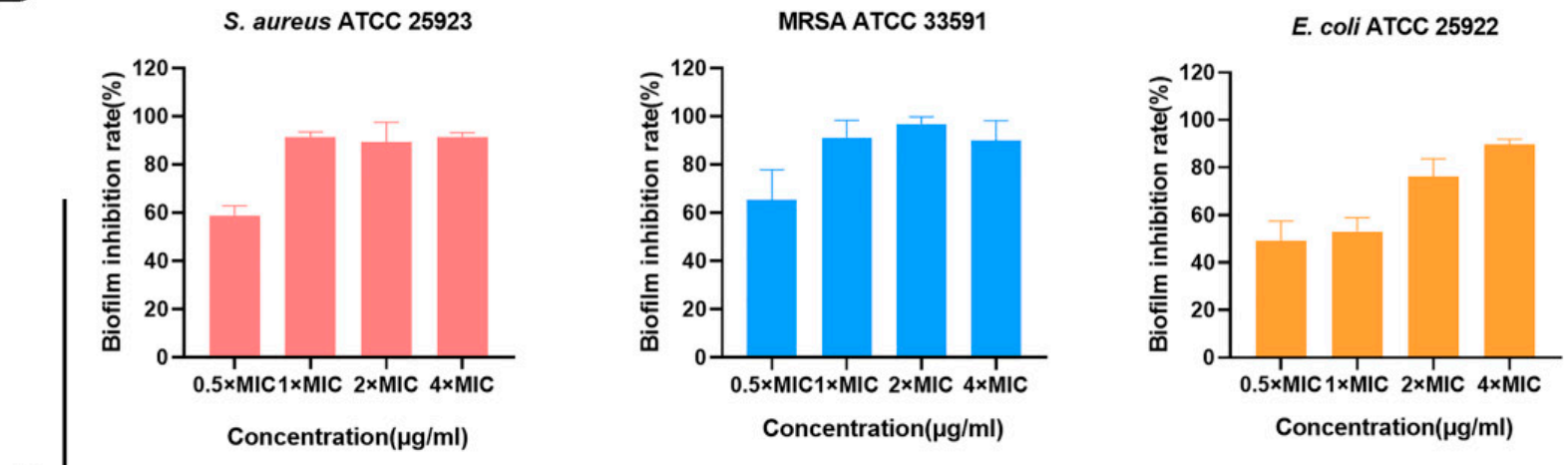

온

P. aeruginosa ATCC 27853

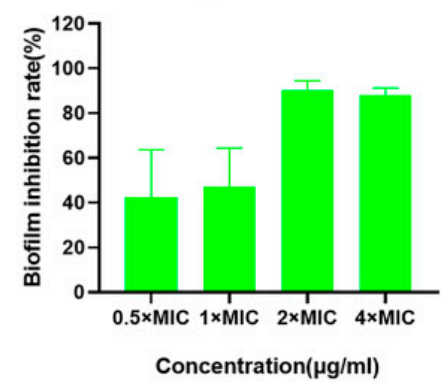

A. baumannii ATCC 19606

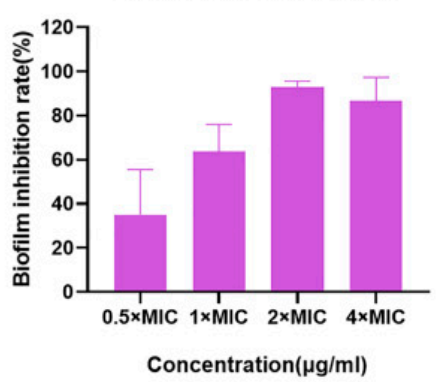

Figure 4. Biofilm inhibitory activity of (A) K65 and (B) K70 against S. aureus ATCC 25923, MRSA ATCC 33591, E. coli ATCC 25922, P. aeruginosa ATCC 27853 and A. baumannii ATCC 19606. 


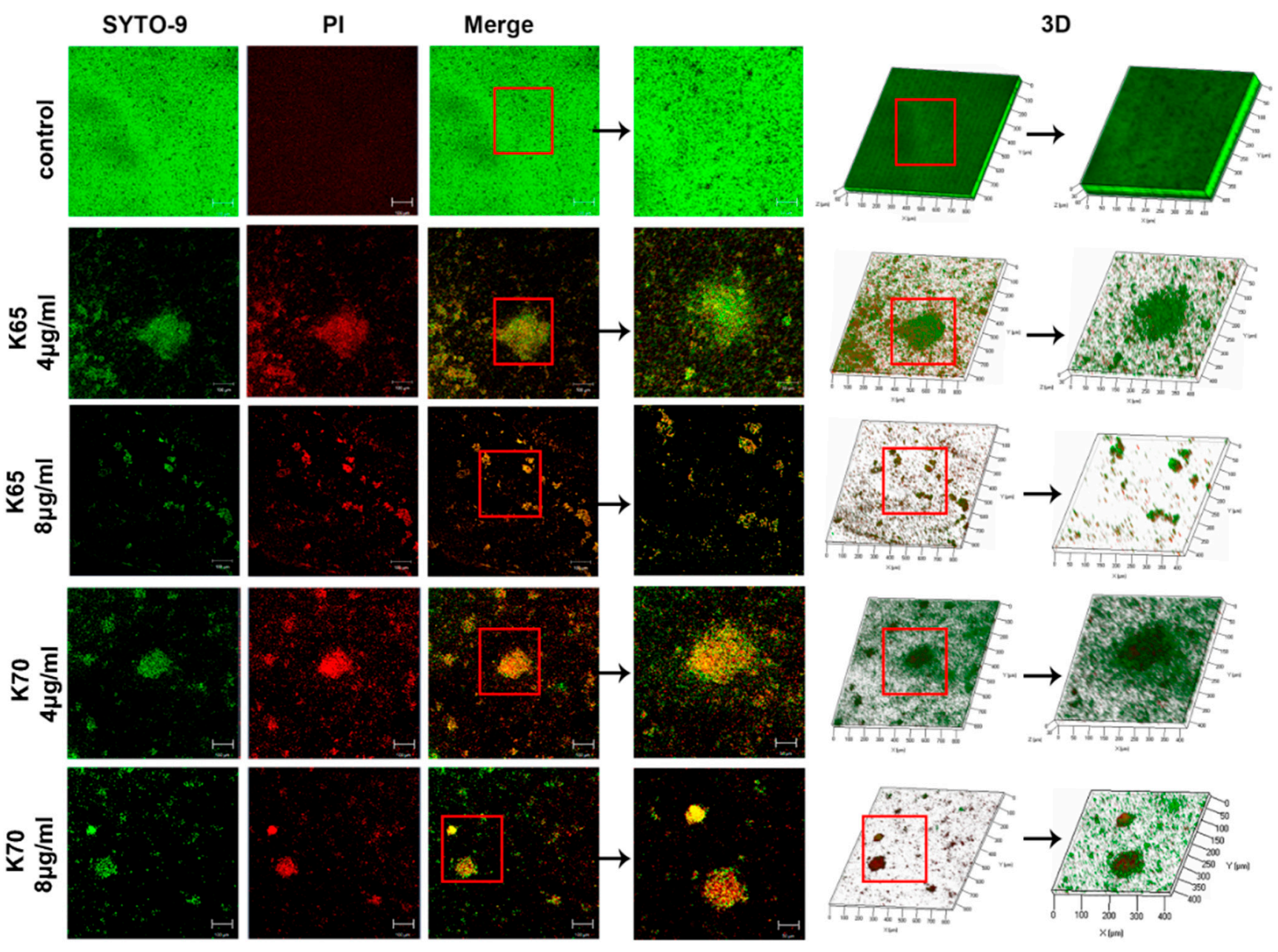

Figure 5. Biofilm inhibitory activity of K65 and K70 against MRSA ATCC 33591 was determined by CLSM using a LIVE/DEAD Biofilm Viability Kit. Bacteria were incubated with these analogs ( $4 \mu \mathrm{g} / \mathrm{mL}$ and $8 \mu \mathrm{g} / \mathrm{mL})$ for $24 \mathrm{~h}$ to form the biofilm. The mixed dyes of PI and SYTO9 $(6 \mu \mathrm{g} / \mathrm{mL})$ were used to stain biofilm dead and live cells. The three-dimensional structures were imaged by the Z-stack mode of the CLSM.

\subsubsection{SEM}

K70 was chosen to observe its antibiofilm effects on MRSA using SEM. As shown in Figure 7, in the control group, the bacteria adhered to form mature biofilms characterized by structured communities instead of individual colonies (Figure 7A). In the low-concentration group $(4 \mu \mathrm{g} / \mathrm{mL})$, the number of biofilm cells were significantly reduced (Figure $7 \mathrm{~B})$. In the high-concentration group $(8 \mu \mathrm{g} / \mathrm{mL})$, the bacteria appeared sporadically and were not enough to form biofilms (Figure 7C). These results indicated that the inhibitory effects of K70 on MRSA biofilm formation were remarkable and concentration-dependent.

\subsection{Membrane Mechanism of Action of Feleucin-K3 Analogs}

In this study, the interactions between the Feleucin-K3 analogs and the cell membrane components were successively investigated to clarify the mode of membrane action of the Feleucin-K3 analogs. In Figure 8A, the coincubation of LPS/LTA with K65 and K70 had a concentration-dependent inhibitory effect. The antimicrobial activity could be completely inhibited when these peptides were bound with high concentrations of LPS/LTA. 

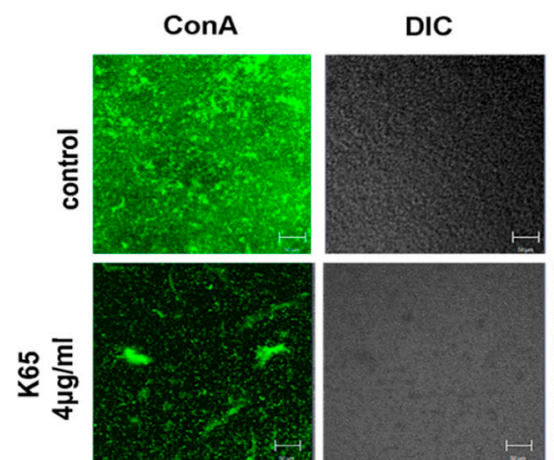

Merge
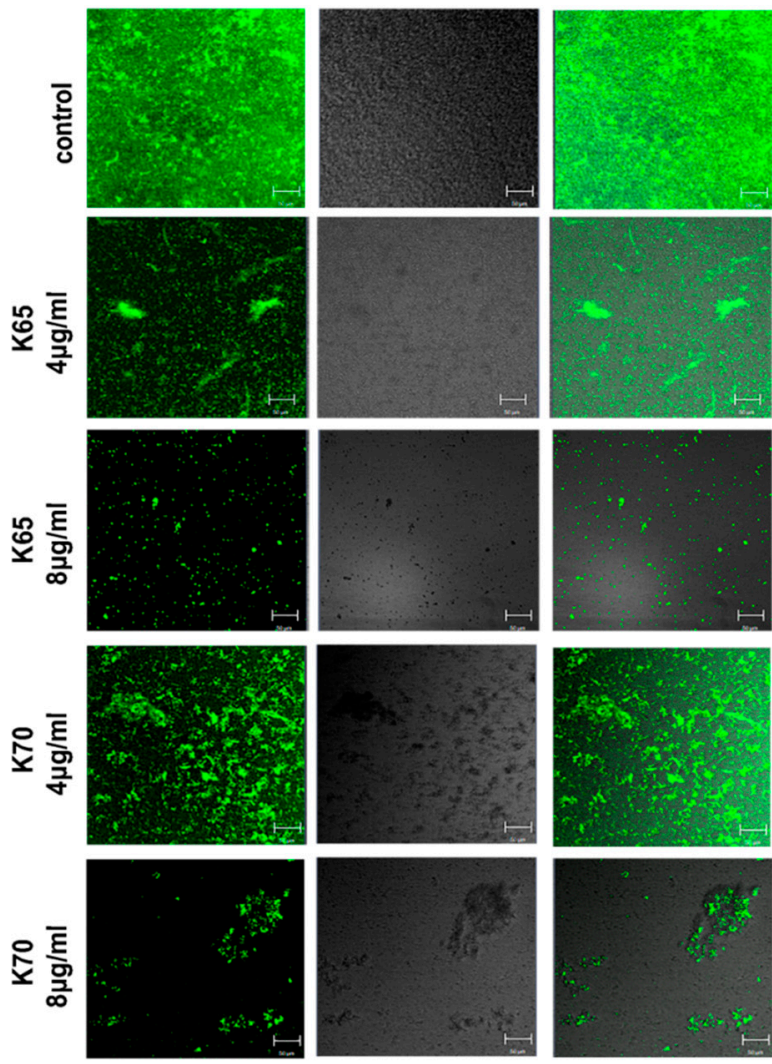
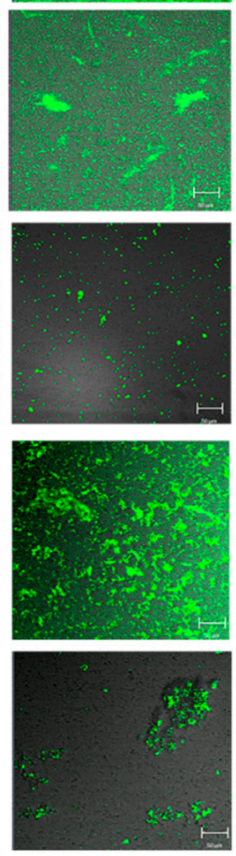

3D
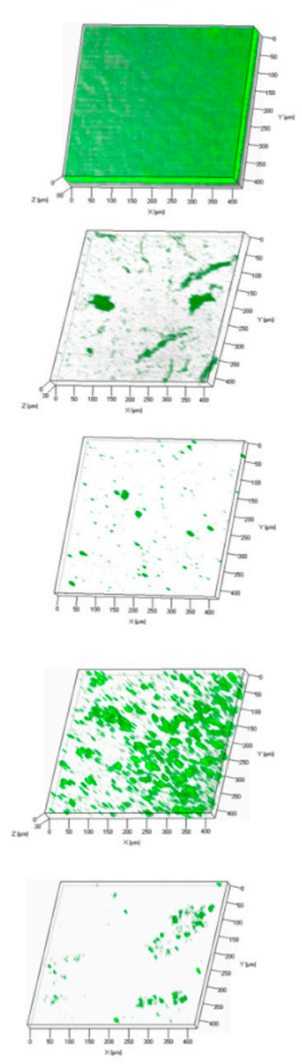

Figure 6. The biofilm inhibitory activity of K65 and K70 against MRSA ATCC 33591 was determined by CLSM using concanavalin A conjugates. The bacteria were incubated with these analogs $(4 \mu \mathrm{g} / \mathrm{mL}$ and $8 \mu \mathrm{g} / \mathrm{mL}$ ) for $24 \mathrm{~h}$ to form the biofilm. Concanavalin A conjugates $(40 \mu \mathrm{g} / \mathrm{mL})$ were used to stain the exopolysaccharide matrix. The three-dimensional structures were imaged by the Z-stack mode of the CLSM.

Then, after the bacterial treatment with different concentrations of analogs, the significantly increased fluorescence of NPN implied a strong damaging effect to the bacterial outer membrane (Figure 8B). Notably, the level of permeabilization induced by high concentrations of K65 and K70 was stronger than that induced by low concentrations.

Cytoplasmic membrane depolarization was detected using DiSC3(5). As shown in Figure 8C, the fluorescence intensity increased rapidly, indicating that the membrane potential dissipated. However, the cytoplasmic membrane depolarization of Gram-negative bacteria induced by the analogs was stronger than that of Gram-positive S. aureus. For E. coli and A. baumannii, the effects of K65 were similar to those of K70. For P. aeruginosa, K65 at high concentrations showed substantially stronger cytoplasmic membrane depolarization than K65 at low concentrations.

The PI uptake abilities of S. aureus and A. baumannii treated with analogs K65 and K70 were analyzed, and the results are shown in Figure 9A. The bacteria treated with analogs K65 and K70 presented significant red signals, implying strong membrane destruction.

Additionally, the membrane-damaging effects of K70 on MRSA were observed using SEM. As shown in Figure 9B, the surface of the cell membrane was rough, shrunken and wrinkled when the MRSA cells were exposed to K70 for $30 \mathrm{~min}$. After $120 \mathrm{~min}$, severe membrane damage, such as membrane surface collapse and the leakage of intracellular components, was observed. In addition, K70 at a high concentration $(4 \times \mathrm{MIC})$ had a more severe damaging effect than that at a low concentration $(2 \times \mathrm{MIC})$, indicating that the damaging effects of K70 on the MRSA membrane were time- and concentration-dependent. 

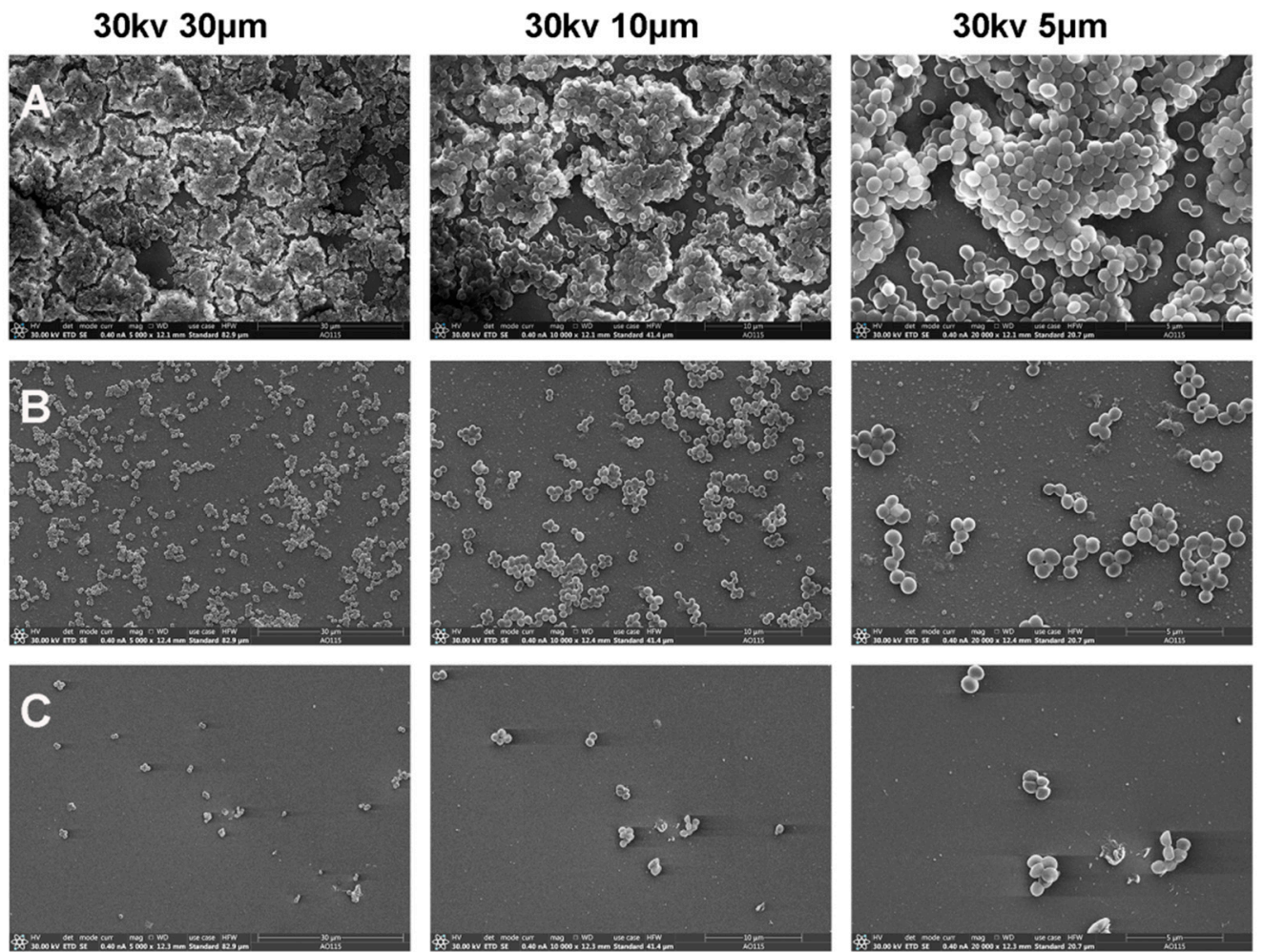

Figure 7. Impact of K70 on the biofilm of MRSA ATCC 33591, as determined by SEM. (A) Untreated biofilm cells, (B) biofilm cells treated with $\mathrm{K} 70$ at $4 \mu \mathrm{g} / \mathrm{mL}$ and (C) biofilm cells treated with $\mathrm{K} 70$ at $8 \mu \mathrm{g} / \mathrm{mL}$.

\subsection{DNA-Binding Affinity}

A DNA-binding assay was used to explore whether the Feleucin-K3 analogs interacted with bacterial genomic DNA. As shown in Figure 9C, both K65 and K70, ranging from $1 \times$ MIC to $8 \times$ MIC, did not hinder the migration of genomic DNA within the agarose gels, indicating that these analogs did not kill the bacteria by combining with genomic DNA.

\subsection{Antibiofilm Activity In Vivo}

In this experiment, K65 and K70 were chosen to determine their ability to treat biofilmassociated infections in mice. S. aureus and MRSA were used as the experimental strains. As shown in Figure 10A, the effects of $\mathrm{K} 65$ and $\mathrm{K} 70(16 \mu \mathrm{g} / \mathrm{mL})$ on S. aureus biofilm inhibition was remarkable. However, compared with the antibiotic AML $(1 \mu \mathrm{g} / \mathrm{mL})$, the inhibitory effects of the peptides were not as potent as that of AML. As shown in Figure $10 \mathrm{~B}, 16 \mu \mathrm{g} / \mathrm{mL}$ of $\mathrm{K} 65$ and $\mathrm{K} 70$ were used as the experimental group. After the treatment for 3 days, the number of MRSA ATCC 33591 cells in each experimental group was significantly reduced. Notably, compared with $64 \mu \mathrm{g} / \mathrm{mL}$ of AML, K65 and K70 inhibited the formation of the MRSA biofilms with higher potency. These results indicated that K65 and K70 had potent biofilm inhibition effects. More importantly, there were remarkable advantages for these analogs compared with antibiotics in the treatment of biofilm infections caused by multidrug-resistant bacteria. 
A

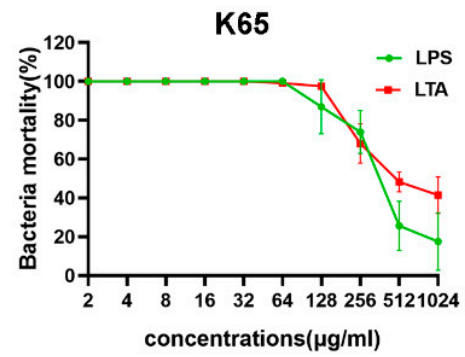

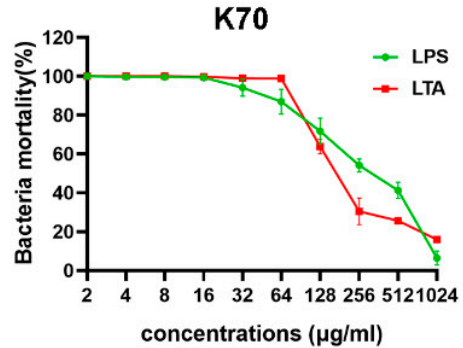

concentrations $(\mu \mathrm{g} / \mathrm{ml})$
B
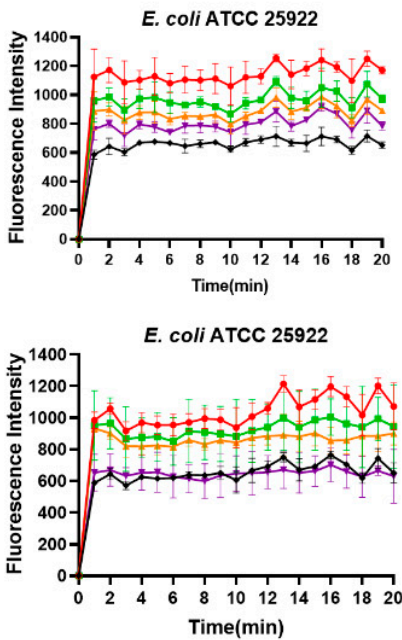

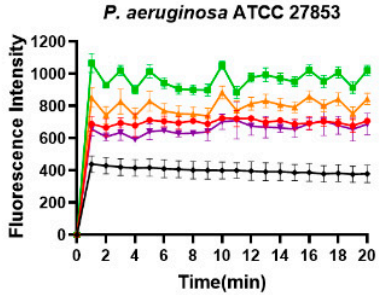

P. aeruginosa ATCC 27853

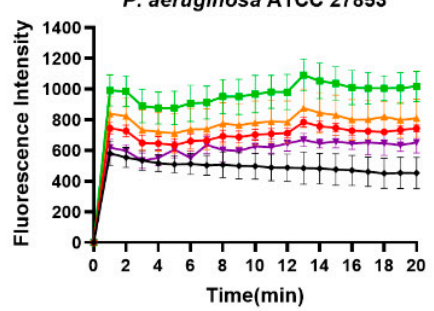

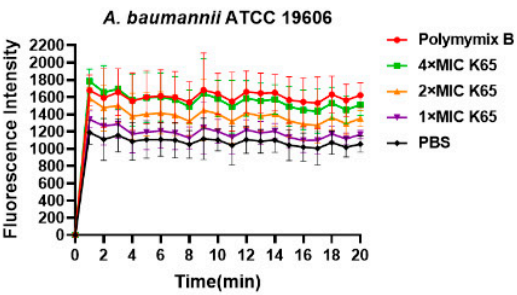

A. baumannii ATCC 19606

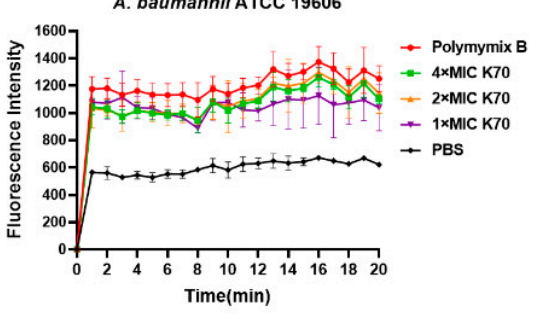

C
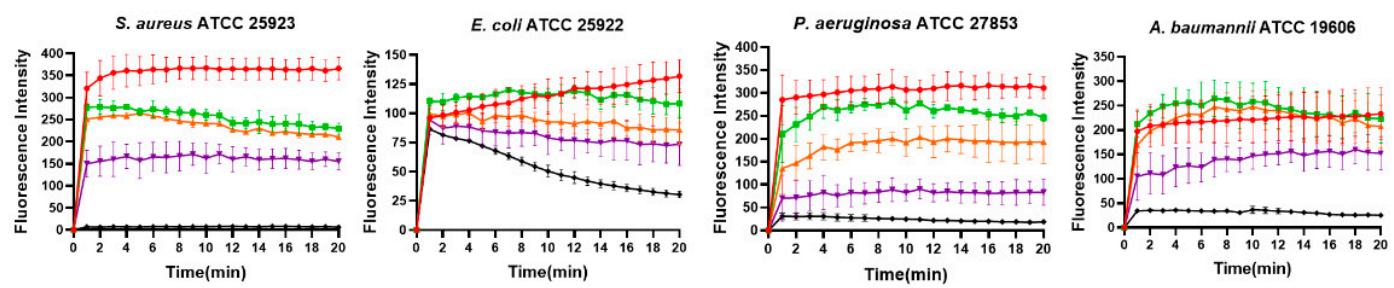

- Control

- 1×MIC K65

- 2×MIC K65

- 4×MIC K65

- $1 \%$ Triton-X100

S. aureus ATCC 25923

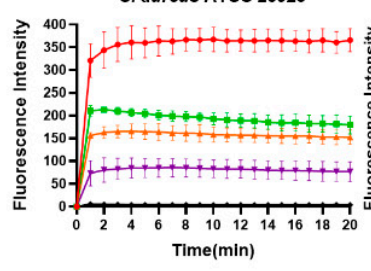

- Control
E. coli ATCC 25922

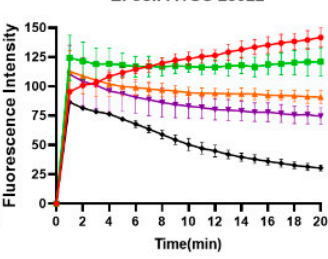

- 1×MIC K70

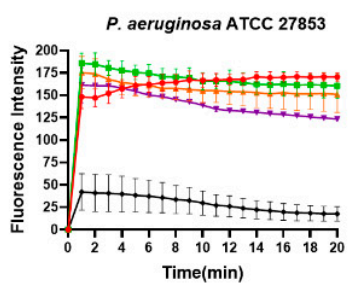

* 2×MIC K70

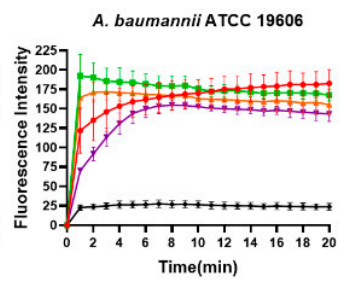

- 4×MIC K70

$\rightarrow 1 \%$ Triton-X100

Figure 8. (A) Bacteria mortality of S. aureus ATCC 25923 and E. coli ATCC 25922 as a function of the LPS/LTA concentrations. (B) The outer membrane permeabilization of E. coli ATCC 25922, P. aeruginosa ATCC 27853 and A. baumannii ATCC 19606 induced by different concentrations of $\mathrm{K} 65$ and K70. (C) The cytoplasmic membrane depolarization of S. aureus ATCC 25923, E. coli ATCC 25922, P. aeruginosa ATCC 27853 and A. baumannii ATCC 19606 induced by different concentrations of K65 and K70. 
A
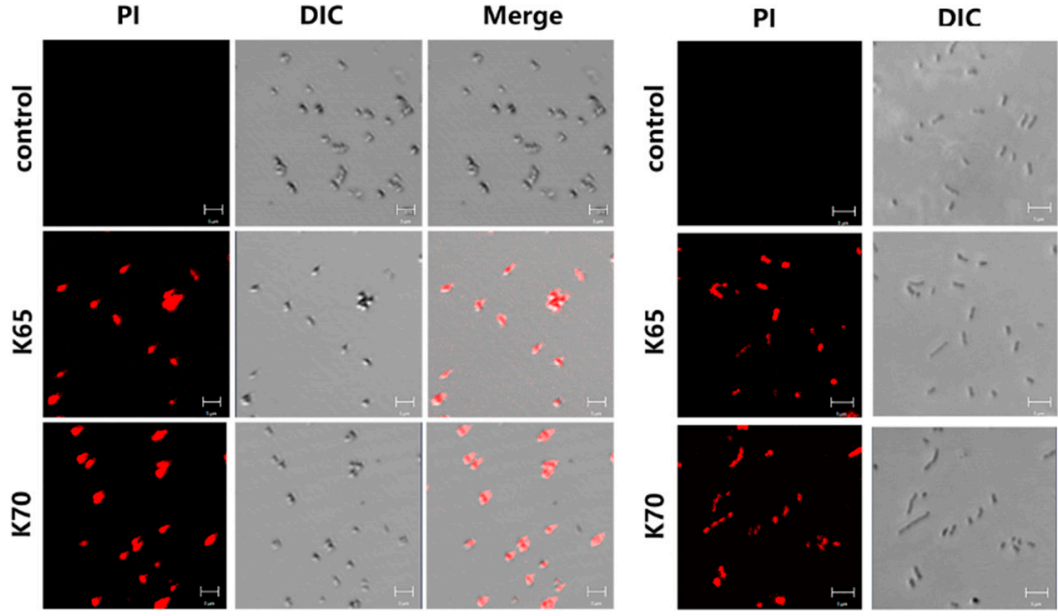

Merge

S. aureus

A. baumannii

B

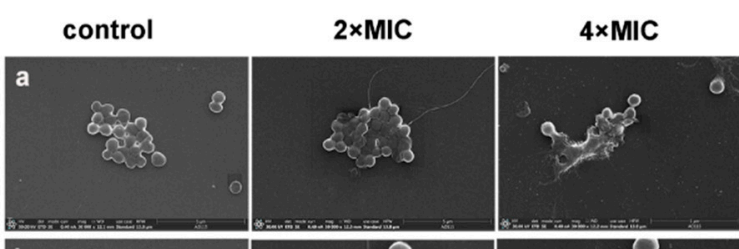

2×MIC

$4 \times$ MIC
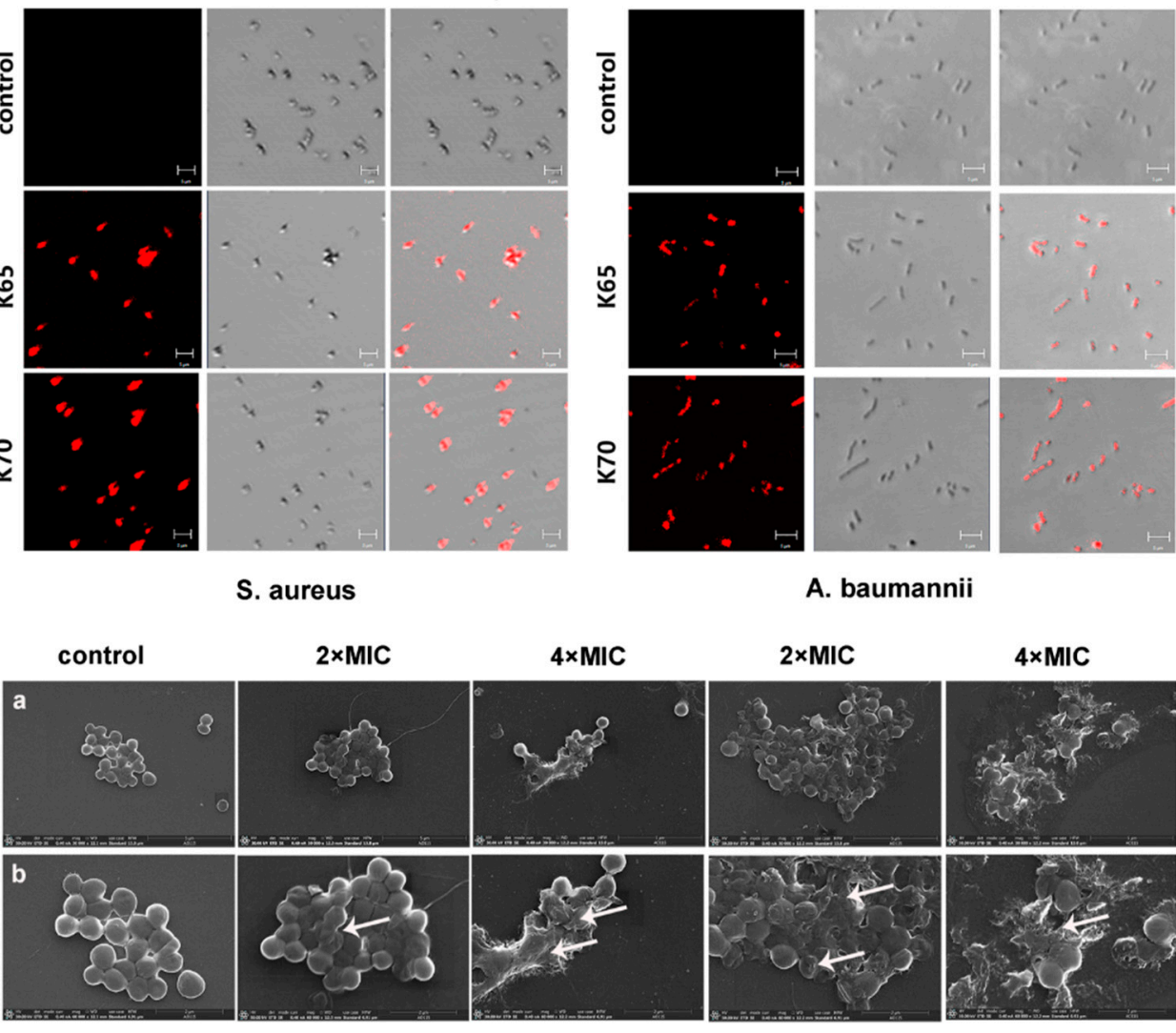

$30 \mathrm{~min}$
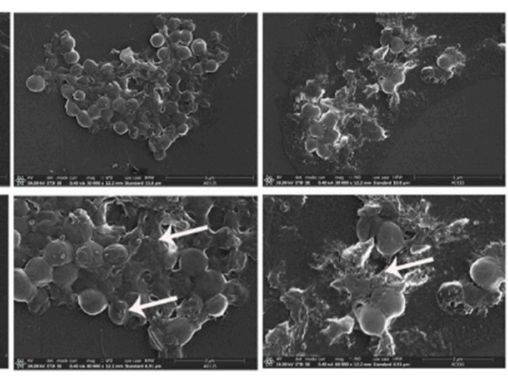

C
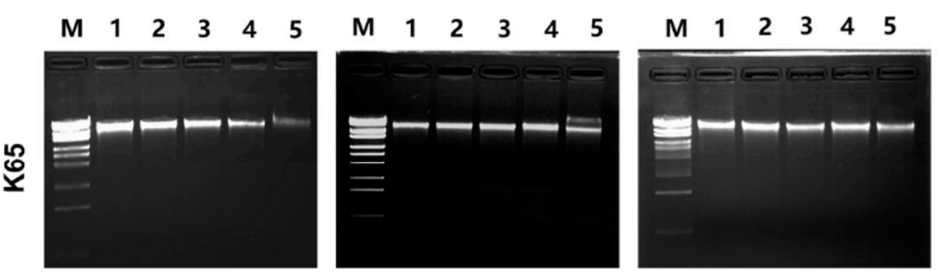

$120 \mathrm{~min}$

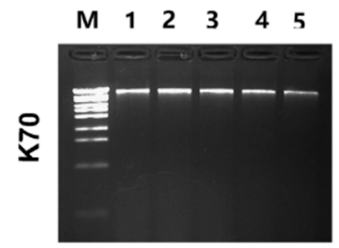

S. aureus

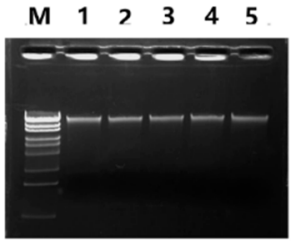

E. coli

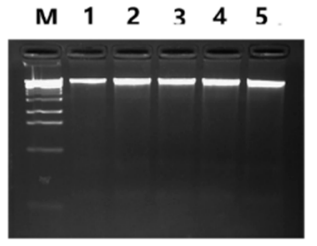

P. aeruginose
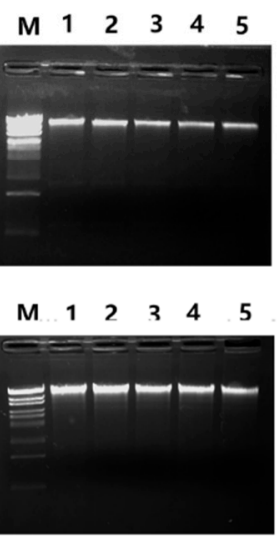

A. baumannii

Figure 9. (A) PI uptake of S. aureus ATCC 25923 and A. baumannii ATCC 19606 treated with K65 and K70 at $4 \times$ MIC for $30 \mathrm{~min}$. (B) SEM micrographs of MRSA ATCC 33591 treated with K70 at $2 \times$ MIC or $4 \times$ MIC for 30 min or 120 min. Arrows indicate that the membrane displayed a rough and irregular atrophy. (a) The magnification is $30,000 \times$. (b) The magnification is $60,000 \times$. (C) The interaction of K65 and K70 with bacterial genomic DNA. The lanes represented the following: lane M, DNA marker ( $\lambda$-EcoT4 I digest); lane 1, DNA only; lane 2, $1 \times$ MIC; lane 3, $2 \times$ MIC; lane 4, $4 \times$ MIC and lane 5, $8 \times$ MIC. 
A

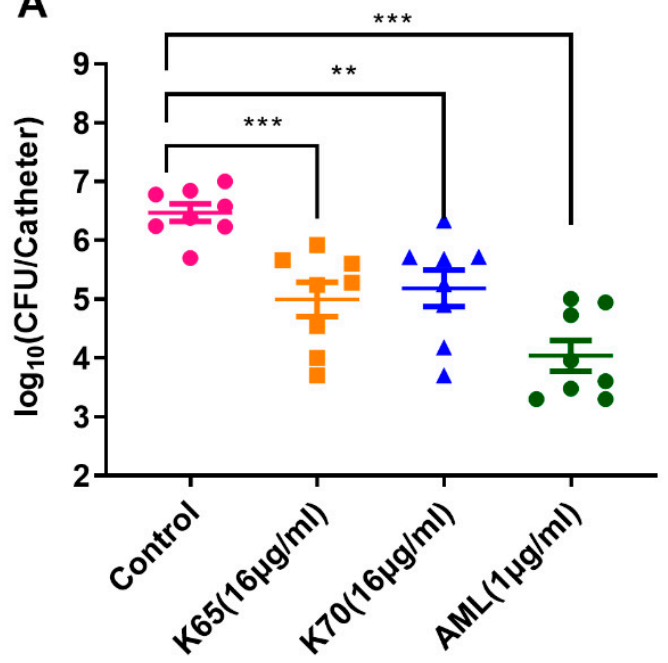

B

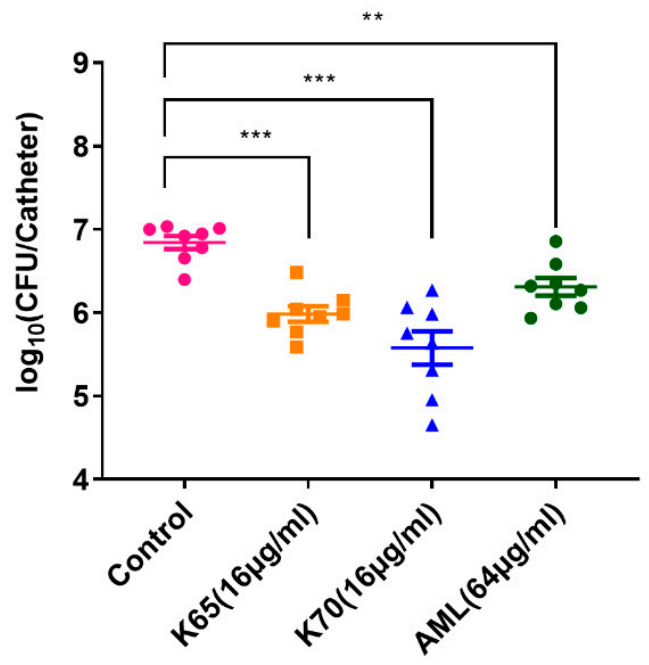

Figure 10. Antibiofilm activity of K65 and K70 in vivo. Catheter biofilm infections caused by S. aureus or MRSA were established. Animals were treated with $100 \mu \mathrm{L}$ of PBS, AML, K65 and K70 injected into the catheter twice a day. After 3 days, the bacterial load in the catheter was calculated. (A) The inhibition effect of the S. aureus ATCC 25923 biofilm. (B) The inhibition effect of the MRSA ATCC 33591 biofilm. The experiments were repeated three times, and the results were consistent. The data represent the mean \pm SD. Statistically significant differences were noted with an asterisk ${ }^{* *} 0.001<p<0.01$ and $\left.{ }^{* * *} p<0.001\right)$.

\section{Discussion}

The introduction of unnatural amino acids may cause major functional differences in AMPs, which, in turn, affects their ability to kill microorganisms and can induce toxicity to host cells [23]. $\alpha$-(4-Pentenyl)-Ala is an unnatural hydrophobic amino acid that affects the hydrophobicity and amphipathicity of entire peptides. Herein, $\alpha$-(4-pentenyl)-Ala was introduced into the short nonapeptide Feleucin-K3. The antimicrobial activity and structure-activity relationships of the synthetic analogs were studied to search for excellent antibacterial lead compounds.

The $T_{R}$ values obtained from RP-HPLC reflect the hydrophobicity. AMPs with greater hydrophobicity generally showed an increase in $T_{R}$ [24]. Among these analogs, the analogs with unnatural hydrophobic amino acid replacements had enhanced hydrophobicity and antimicrobial activity. K63 had the highest hydrophobicity but the worst antimicrobial activity among the analogs. The results displayed a U-shaped relationship between the activity of the analogs and their hydrophobicity [25]. Increasing the hydrophobicity could enhance the antimicrobial activity until an optimal hydrophobicity threshold was reached [26]. This is consistent with the known antimicrobial mechanism. AMPs with higher hydrophobicity can be inserted into a hydrophobic core, resulting in the disruption of the membrane structure or cell lysis [3]. AMPs with a hydrophobicity that is too high might self-aggregate, resulting in a decrease in antimicrobial activity [27]. In addition, excessive hydrophobicity was highly correlated with hemolytic activity. In this study, K71 had greatly enhanced hydrophobicity. However, this excessive hydrophobicity might be a reason why its hemolytic activity was significantly higher than that of the other analogs. Compared with the other analogs, K65 and K70 had enhanced hydrophobicity and significantly reduced hemolytic activity.

AMP amphipathicity has been considered a feature that directly affects antimicrobial and hemolytic activity [28]. In this experiment, these analogs with $\alpha$-(4-pentenyl)-Ala substitution had decreased $\alpha$-helical contents and enhanced antimicrobial activity compared with Feleucin-K3. However, they showed a significant difference in hemolytic activity. The influence of $\alpha$-(4-pentenyl)-Ala substitution on hemolytic activity was associated with the $\alpha$-helical content and the position of this substitution [29]. The $\alpha$-helical contents of the Feleucin-K3 analogs were lower than that of Feleucin-K3, implying that the introduction of 
this unnatural amino acid led to a decrease in amphipathicity. Imperfect amphiphilicity may contribute to a reduction in hemolytic activity [30]. Furthermore, it was worth noting that analogs in which substitutions occurred at the N-terminus (K65) and C-terminus (K70) had lower hemolytic activity than analogs where the substitutions occurred near the center of the sequence. In particular, it was found that the C-terminal residue (leucine) exchange with $\alpha$-(4-pentenyl)-Ala not only enhanced the antimicrobial activity but also strongly impaired the hemolytic activity. This might be because K70 had an excellent hydrophobic/hydrophilic balance, which was optimal for peptide selectivity to the cell and interactions with the membrane core penetrating into the cell [31].

Many reports showed that peptides with reasonably modulated $\alpha$-helical structures displayed great selectivity against prokaryotic and eukaryotic cells [19]. In our previous study, K59 was an analog of the $\alpha$-(4-pentenyl)-Ala substitution that took place in the fourth position [12]. K70 exhibited significant antimicrobial activity without hemolytic activity, whereas K59 showed nonnegligible hemolytic activity at high concentrations. We guessed that decreasing the $\alpha$-helical content (15.62\%) of K70 might cause lower hemolytic activity compared with K59 (41.93\%). Moreover, the introduction of unnatural amino acid $\alpha$-(4pentenyl)-Ala was beneficial for the resistance against proteases, regardless of whether the substitution occurred in terminus (K65 and K70) and near the center of the sequence (K59).

Cations in physiological salt environments, such as $\mathrm{Na}^{+}$, hamper electrostatic interactions, resulting in the resistance of AMPs in high-salt environments [32,33]. Moreover, natural AMPs are susceptible to degradation by proteases or a combination with serum albumin, resulting in impaired antimicrobial activity [34]. Modifying natural amino acids can increase their resistance to proteolytic degradation and circumvent their susceptibility [7]. In line with our results, the Feleucin- $\mathrm{K} 3$ analogs maintained their antimicrobial activity, especially against MRSA. These peptides had enhanced stability compared with Feleucin-K3 in the presence of human serum (Figure 2). These analogs showed low $\alpha$-helical contents but displayed an enhanced $\beta$-strand content in comparison with Feleucin-K3 (Table S1). Therefore, we speculated that this was possibly because $\alpha$-(4-pentenyl)-Ala, an alanine analog with a long side chain alkene, was introduced to Feleucin-K3. This special, long hydrophobic alkene side chain substituent not only affected the hydrophobicity but also considerably affected the secondary structure. The hydrophobicity and secondary structure are closely intertwined in regard to the stability of AMPs.

Frog skin is the most abundant source of AMPs, such as Magainin, Temporin and Esculentin, that have been found and widely reported [35,36]. Magainin 2 is a membraneactive AMP that was isolated from the skin of the African clawed frog. It was confirmed that this AMP can kill bacteria via electrostatic attractions and form a pore but cannot retard the migration of DNA [37]. The mode of action was similar to that of the Fekeucin-K3 analogs tested in this study. However, the new synthetic Feleucin-K3 analogs had more effective antimicrobial activity than Magainin 2. In a recent study, $\alpha$-(4-pentenyl)-Ala was reported being used for modifying Magainin 2. The introduction of $\alpha$-(4-pentenyl)-Ala in the $i / i+4$ position could stabilize its helical structure and improve the bioactivity [38]. In this study, although introducing the $\alpha$-(4-Pentenyl)-Ala with a hydrocarbon side chain decreased the $\alpha$-helical content, it also enhanced the antimicrobial activity and reduced the toxicity.

Biofilms can be simply defined as a structured community characterized by cells that are encased in a matrix of self-produced EPSs [39]. Bacterial biofilms present a high resistance to antibiotics, and their antibacterial tolerance is 10- to 1000-fold higher than that of planktonic bacteria. Costerton et al. pointed out that an inherent biofilm resistance to antibiotics is the main reason for many persistent and chronic bacterial infections [40]. In our study, K65 and K70 showed significant antibiofilm activity in vitro/in vivo. Additionally, the antibiofilm activity of these analogs against MRSA at low concentrations was better than the effects of AML on MRSA at high concentrations in biofilm-associated infections. We speculated that the rapid killing ability of these peptides was crucial, which extremely reduced the adhesion of the biofilm bacteria. Moreover, K65 and K70 significantly inhib- 
ited the formation of the exopolysaccharides associated with biofilm maturation, thereby reducing the development of bacterial resistance by means of antibiofilms [41].

For the peptide-membrane interaction, LPS and LTA, as the main anionic polymers in the bacterial membrane, were confirmed to bind with high affinity to the positively charged analogs. These polymers might act to trap the AMPs, facilitating the penetration of the cell wall [42]. Subsequently, the outer membrane permeability and cytoplasmic membrane depolarization induced by K65 and K70 rapidly increased and had significant time- and concentration-dependent effects, indicating that the peptide-membrane interaction might be related to channel or pore formation, thus leading to cellular component leakage and cell death [43]. Interestingly, depolarization of the S. aureus cytoplasmic membrane induced by the Feleucin-K3 analogs was weaker than that in Gram-negative bacteria. An explanation for this result might be the structural differences between the bacterial cell walls. AMPs competitively displace the divalent ions $\left(\mathrm{Mg}^{2+}\right)$ and calcium ions $\left(\mathrm{Ca}^{2+}\right)$ of the outer membrane by penetrating both the outer and cytoplasmic membranes in Gram-negative bacteria [44]. For Gram-positive bacteria, AMPs can cross peptidoglycan and other components before depolarization of the cytoplasmic membrane [45]. The PI uptake and SEM assays also supported that analogs K65 and K70 displayed antimicrobial activity mainly through membrane disruption mechanisms.

\section{Conclusions}

In our study, a series of (4-pentenyl)-Ala-substituted Feleucin-K3 analogs were designed and synthesized. Among the synthetic analogs, we successfully screened K65 and K70, whose N-terminal and C-terminal residues were substituted by (4-pentenyl)-Ala, respectively, which showed improved antimicrobial activity, stability, low hemolytic activity and AMR. In particular, K70 had an excellent hydrophobic/hydrophilic balance, producing no hemolytic activity at high concentrations. Considering the role of biofilms in AMR, the antibiofilm activity of K65 and K70 was estimated. Our results indicated that these compounds effectively inhibited biofilm formation in vitro/in vivo and that the inhibitory activity against MRSA was better than that of traditional antibiotics. In addition, K65 and K70 exhibited a strong membrane destabilization ability and damage to the membrane integrity, leading to bacterial death. In summary, these results demonstrated that the introduction of the unnatural amino acid $\alpha$-(4-pentenyl)-Ala was a potential strategy in developing potent antimicrobial agents.

Supplementary Materials: The following are available online at https:/ / www.mdpi.com/article/10 .3390/biom11050761/s1: Table S1: Circular dichroism spectrum date of Feleucin-K3 and its analogs in PBS and 50\% TFE.

Author Contributions: Conceptualization, J.X.; funding acquisition, B.Z. and J.X.; investigation, X.G., T.Y. and J.R.; methodology, X.G., T.Y. and J.R.; software, X.Y., X.P. and J.D.; supervision, W.S., W.Y. and J.X.; writing — original draft, X.G. and writing—review and editing, J.X. All authors have read and agreed to the published version of the manuscript.

Funding: This study was supported by the National Natural Science Foundation of China (No. 81602945 and 81673283), the CAMS Innovation Fund for Medical Sciences (CIFMS) (No. 2019I2M-5-074), the Program for the Ministry of Education "Peptide Drugs" Innovation Team (No. IRT_15R27), the Gansu Science and Technology Program (No. 18JR2RA031) and the Lanzhou Science and Technology Bureau (No. 2019-4-4).

Institutional Review Board Statement: The study was strictly complied with the Guide for the Care and Use of Laboratory Animals of the National Institutes of Health and was approved by the Ethics Committee of Lanzhou University (SYXK GAN 2018-0002).

Informed Consent Statement: Not applicable.

Data Availability Statement: Not applicable.

Acknowledgments: The authors thank Gansu Provincial People's Hospital for providing the multidrugresistant strains. 
Conflicts of Interest: The authors declare no conflict of interest.

\section{References}

1. Aminov, R. History of antimicrobial drug discovery: Major classes and health impact. Biochem. Pharmacol. 2017, 133, 4-19. [CrossRef] [PubMed]

2. Blair, J.M.A.; Webber, M.A.; Baylay, A.J.; Ogbolu, D.O.; Piddock, L.J.V. Molecular mechanisms of antibiotic resistance. Nat. Rev. Microbiol. 2015, 13, 42-51. [CrossRef] [PubMed]

3. Wang, J.; Dou, X.; Song, J.; Lyu, Y.; Zhu, X.; Xu, L.; Li, W.; Shan, A. Antimicrobial peptides: Promising alternatives in the post feeding antibiotic era. Med. Res. Rev. 2019, 39, 831-859. [CrossRef]

4. Allen, K.D.; Green, H.T. Hospital Outbreak of Multiresistant Acinetobacter-Anitratus-An Airborne Mode of Spread. J. Hosp. Infect. 1987, 9, 110-119. [CrossRef]

5. Mason, A.J.; Chotimah, I.N.H.; Bertani, P.; Bechinger, B. A spectroscopic study of the membrane interaction of the antimicrobial peptide pleurocidin. Mol. Membr. Biol. 2006, 23, 185-194. [CrossRef]

6. Shafee, T.M.A.; Lay, F.T.; Phan, T.K.; Anderson, M.A.; Hulett, M.D. Convergent evolution of defensin sequence, structure and function. Cell. Mol. Life Sci. 2017, 74, 663-682. [CrossRef] [PubMed]

7. Svenson, J.; Stensen, W.; Brandsdal, B.-O.; Haug, B.E.; Monrad, J.; Svendsen, J.S. Antimicrobial Peptides with Stability toward Tryptic Degradation. Biochemistry 2008, 47, 3777-3788. [CrossRef]

8. Wang, C.W.; Yip, B.S.; Cheng, H.T.; Wang, A.H.; Chen, H.L.; Cheng, J.W.; Lo, H.J. Increased potency of a novel D-betanaphthylalanine-substituted antimicrobial peptide against fluconazole-resistant fungal pathogens. FEMS Yeast Res. 2009, 9, 967-970. [CrossRef]

9. Gonzalez, R.; Mendive-Tapia, L.; Pastrian, M.B.; Albericio, F.; Lavilla, R.; Cascone, O.; Iannucci, N.B. Enhanced antimicrobial activity of a peptide derived from human lysozyme by arylation of its tryptophan residues. J. Pept. Sci. 2016, 22, 123-128. [CrossRef] [PubMed]

10. Hou, X.J.; Du, Q.; Li, R.J.; Zhou, M.; Wang, H.; Wang, L.; Guo, C.; Chen, T.B.; Shaw, C. Feleucin-BO1: A Novel Antimicrobial Non-Apeptide Amide from the Skin Secretion of the Toad, Bombina orientalis, and Design of a Potent Broad-Spectrum Synthetic Analogue, Feleucin-K3. Chem. Biol. Drug Des. 2015, 85, 259-267. [CrossRef] [PubMed]

11. Xie, J.; Li, Y.; Li, J.; Yan, Z.; Wang, D.; Guo, X.; Zhang, J.; Zhang, B.; Mou, L.; Yang, W.; et al. Potent effects of amino acid scanned antimicrobial peptide Feleucin-K3 analogs against both multidrug-resistant strains and biofilms of Pseudomonas aeruginosa. Amino Acids 2018, 50, 1471-1483. [CrossRef]

12. Guo, X.; Rao, J.; Yan, T.; Zhang, B.; Yang, W.; Sun, W.; Xie, J. Feleucin-K3 Analogue with an $\alpha$-(4-Pentenyl)-Ala Substitution at the Key Site Has More Potent Antimicrobial and Antibiofilm Activities in Vitro and in Vivo. ACS Infect. Dis. 2021, 7, 64-78. [CrossRef]

13. Wang, J.; Song, J.; Yang, Z.; He, S.; Yang, Y.; Feng, X.; Dou, X.; Shan, A. Antimicrobial Peptides with High Proteolytic Resistance for Combating Gram-Negative Bacteria. J. Med. Chem. 2019, 62, 2286-2304. [CrossRef]

14. Ling, L.L.; Schneider, T.; Peoples, A.J.; Spoering, A.L.; Engels, I.; Conlon, B.P.; Mueller, A.; Schaberle, T.F.; Hughes, D.E.; Epstein, S.; et al. A new antibiotic kills pathogens without detectable resistance. Nature 2015, 517, 455-459. [CrossRef] [PubMed]

15. Zhong, C.; Zhu, N.; Zhu, Y.; Liu, T.; Gou, S.; Xie, J.; Yao, J.; Ni, J. Antimicrobial peptides conjugated with fatty acids on the side chain of D-amino acid promises antimicrobial potency against multidrug-resistant bacteria. Eur. J. Pharm. Sci. 2020, 141, 105123. [CrossRef]

16. Xie, J.; Li, Y.; Guo, X.; Rao, J.; Yan, T.; Mou, L.; Wu, X.; Xie, X.; Yang, W.; Zhang, B. CPF-C1 analog with effective antimicrobial and antibiofilm activities against Staphylococcus aureus including MRSA. Biochimie 2020, 176, 1-11. [CrossRef]

17. Shao, C.; Li, W.; Lai, Z.; Akhtar, M.U.; Dong, N.; Shan, A.; Ma, D. Effect of terminal arrangement of tryptophan on biological activity of symmetric alpha-helix-forming peptides. Chem. Biol. Drug Des. 2019, 94, 2051-2063. [CrossRef] [PubMed]

18. Sangalli-Leite, F.; Scorzoni, L.; Alves de Paula, E.S.A.C.; da Silva, J.F.; de Oliveira, H.C.; de Lacorte Singulani, J.; Gullo, F.P.; Moraes da Silva, R.; Regasini, L.O.; Siqueira da Silva, D.H.; et al. Synergistic effect of pedalitin and amphotericin B against Cryptococcus neoformans by in vitro and in vivo evaluation. Int. J. Antimicrob. Agents 2016, 48, 504-511. [CrossRef] [PubMed]

19. Chou, S.; Wang, J.; Shang, L.; Akhtar, M.U.; Wang, Z.; Shi, B.; Feng, X.; Shan, A. Short, symmetric-helical peptides have narrow-spectrum activity with low resistance potential and high selectivity. Biomater. Sci. 2019, 7, 2394-2409. [CrossRef]

20. Mwangi, J.; Yin, Y.; Wang, G.; Yang, M.; Li, Y.; Zhang, Z.; Lai, R. The antimicrobial peptide ZY4 combats multidrug-resistant Pseudomonas aeruginosa and Acinetobacter baumannii infection. Proc. Natl. Acad. Sci. USA 2019. [CrossRef] [PubMed]

21. De Breij, A.; Riool, M.; Cordfunke, R.A.; Malanovic, N.; de Boer, L.; Koning, R.I.; Ravensbergen, E.; Franken, M.; van der Heijde, T.; Boekema, B.K.; et al. The antimicrobial peptide SAAP-148 combats drug-resistant bacteria and biofilms. Sci. Transl. Med. 2018, 10, 14. [CrossRef]

22. Svendsen, J.S.M.; Grant, T.M.; Rennison, D.; Brimble, M.A.; Svenson, J. Very Short and Stable Lactoferricin-Derived Antimicrobial Peptides: Design Principles and Potential Uses. Acc. Chem. Res. 2019, 52, 749-759. [CrossRef] [PubMed]

23. Hilpert, K.; Elliott, M.R.; Volkmer-Engert, R.; Henklein, P.; Donini, O.; Zhou, Q.; Winkler, D.F.; Hancock, R.E. Sequence requirements and an optimization strategy for short antimicrobial peptides. Chem. Biol. 2006, 13, 1101-1107. [CrossRef]

24. Krokhin, O.V.; Spicer, V. Peptide Retention Standards and Hydrophobicity Indexes in Reversed-Phase High-Performance Liquid Chromatography of Peptides. Anal. Chem. 2009, 81, 9522-9530. [CrossRef] 
25. Chen, Y.X.; Guarnieri, M.T.; Vasil, A.I.; Vasil, M.L.; Mant, C.T.; Hodges, R.S. Role of peptide hydrophobicity in the mechanism of action of alpha-helical antimicrobial peptides. Antimicrob. Agents Chemother. 2007, 51, 1398-1406. [CrossRef]

26. Sun, J.B.; Xia, Y.Q.; Li, D.; Du, Q.; Liang, D.H. Relationship between peptide structure and antimicrobial activity as studied by de novo designed peptides. BBA-Biomembranes 2014, 1838, 2985-2993. [CrossRef] [PubMed]

27. Pasupuleti, M.; Schmidtchen, A.; Malmsten, M. Antimicrobial peptides: Key components of the innate immune system. Crit. Rev. Biotechnol. 2012, 32, 143-171. [CrossRef]

28. Wolcott, R.D.; Rhoads, D.D.; Bennett, M.E.; Wolcott, B.M.; Gogokhia, L.; Costerton, J.W.; Dowd, S.E. Chronic wounds and the medical biofilm paradigm. J. Wound Care 2010, 19, 45-53. [CrossRef] [PubMed]

29. Liu, T.; Zhu, N.; Zhong, C.; Zhu, Y.; Gou, S.; Chang, L.; Bao, H.; Liu, H.; Zhang, Y.; Ni, J. Effect of N-methylated and fatty acid conjugation on analogs of antimicrobial peptide Anoplin. Eur. J. Pharm. Sci. 2020, 152, 105453. [CrossRef]

30. Hollmann, A.; Martínez, M.; Noguera, M.E.; Augusto, M.T.; Disalvo, A.; Santos, N.C.; Semorile, L.; Maffía, P.C. Role of amphipathicity and hydrophobicity in the balance between hemolysis and peptide-membrane interactions of three related antimicrobial peptides. Colloids Surf. B Biointerfaces 2016, 141, 528-536. [CrossRef]

31. Zelezetsky, I.; Tossi, A. Alpha-helical antimicrobial peptides-using a sequence template to guide structure-activity relationship studies. Biochim. Biophys. Acta 2006, 1758, 1436-1449. [CrossRef]

32. Torres, M.D.T.; Sothiselvam, S.; Lu, T.K.; de la Fuente-Nunez, C. Peptide Design Principles for Antimicrobial Applications. J. Mol. Biol. 2019, 431, 3547-3567. [CrossRef] [PubMed]

33. Findlay, B.; Zhanel, G.G.; Schweizer, F. Cationic Amphiphiles, a New Generation of Antimicrobials Inspired by the Natural Antimicrobial Peptide Scaffold. Antimicrob. Agents Chemother. 2010, 54, 4049-4058. [CrossRef]

34. Svenson, J.; Brandsdal, B.-O.; Stensen, W.; Svendsen, J.S. Albumin Binding of Short Cationic Antimicrobial Micropeptides and Its Influence on the in Vitro Bactericidal Effect. J. Med. Chem. 2007, 50, 3334-3339. [CrossRef] [PubMed]

35. Kim, M.K.; Kang, N.; Ko, S.J.; Park, J.; Park, E.; Shin, D.W.; Kim, S.H.; Lee, S.A.; Lee, J.I.; Lee, S.H.; et al. Antibacterial and Antibiofilm Activity and Mode of Action of Magainin 2 against Drug-Resistant Acinetobacter baumannii. Int. J. Mol. Sci. 2018, 19, 3041. [CrossRef]

36. Lazzaro, B.P.; Zasloff, M.; Rolff, J. Antimicrobial peptides: Application informed by evolution. Science 2020, 368. [CrossRef]

37. Tamba, Y.; Yamazaki, M. Magainin 2-Induced Pore Formation in the Lipid Membranes Depends on Its Concentration in the Membrane Interface. J. Phys. Chem. B 2009, 113, 4846-4852. [CrossRef] [PubMed]

38. Hirano, M.; Saito, C.; Yokoo, H.; Goto, C.; Kawano, R.; Misawa, T.; Demizu, Y. Development of Antimicrobial Stapled Peptides Based on Magainin 2 Sequence. Molecules 2021, 26, 444. [CrossRef]

39. Arciola, C.R.; Campoccia, D.; Speziale, P.; Montanaro, L.; Costerton, J.W. Biofilm formation in Staphylococcus implant infections. A review of molecular mechanisms and implications for biofilm-resistant materials. Biomaterials 2012, 33, 5967-5982. [CrossRef]

40. Costerton, J.W.; Stewart, P.S.; Greenberg, E.P. Bacterial biofilms: A common cause of persistent infections. Science 1999, 284, 1318-1322. [CrossRef]

41. Hoiby, N.; Bjarnsholt, T.; Givskov, M.; Molin, S.; Ciofu, O. Antibiotic resistance of bacterial biofilms. Int. J. Antimicrob. Agents 2010, 35, 322-332. [CrossRef] [PubMed]

42. Malanovic, N.; Lohner, K. Gram-positive bacterial cell envelopes: The impact on the activity of antimicrobial peptides. Biochim. Biophys. Acta 2016, 1858, 936-946. [CrossRef]

43. Yang, Y.; Wang, C.X.; Gao, N.; Lyu, Y.F.; Zhang, L.C.; Zhang, S.J.; Wang, J.J.; Shan, A.S. A Novel Dual-Targeted alpha-Helical Peptide With Potent Antifungal Activity Against Fluconazole-Resistant Candida albicans Clinical Isolates. Front. Microbiol. $2020,11$. [CrossRef] [PubMed]

44. Watson, J.L.; Gillies, E.R. Amphipathic beta-Strand Mimics as Potential Membrane Disruptive Antibiotics. J. Org. Chem. 2009, 74, 5953-5960. [CrossRef] [PubMed]

45. Zhu, X.; Dong, N.; Wang, Z.Y.; Ma, Z.; Zhang, L.C.; Ma, Q.Q.; Shan, A.S. Design of imperfectly amphipathic alpha-helical antimicrobial peptides with enhanced cell selectivity. Acta Biomater. 2014, 10, 244-257. [CrossRef] [PubMed] 